\title{
RETARDATION OF URANIUM AND THORIUM BY A CEMENTITIOUS BACKFILL DEVELOPED FOR RADIOACTIVE WASTE DISPOSAL
}

M. Felipe-Sotelo ${ }^{\mathrm{a} *}$, J. Hinchliff $^{\mathrm{b}}$, L.P. Field ${ }^{\mathrm{c}}$, A.E., Milodowski ${ }^{\mathrm{c}}$, O. Preedy ${ }^{\mathrm{d}}$, D. Read ${ }^{\mathrm{a}, \mathrm{e}}$

${ }^{a}$ Department of Chemistry, University of Surrey, Guildford, GU2 7XH, United Kingdom.

b JH Consulting, Colerne, Broadgate Lane, Kelham, Newark, Notts., NG23 5RZ, United Kingdom.

${ }^{c}$ British Geological Survey, Keyworth, Nottingham, NG12 5GG, United Kingdom.

d Department of Chemistry, Loughborough University, Loughborough, LE11 3TU, United Kingdom.

${ }^{\mathrm{e}}$ National Physical Laboratory, Hampton Road, Teddington, Middlesex, TW11, United Kingdom

* Corresponding author: m.felipe-sotelo@ surrey.ac.uk

\begin{abstract}
The solubility of uranium and thorium has been measured under the conditions anticipated in a cementitious, geological disposal facility for low and intermediate level radioactive waste. Similar solubilities were obtained for thorium in all media, comprising $\mathrm{NaOH}, \mathrm{Ca}(\mathrm{OH})_{2}$ and water equilibrated with a cement designed as repository backfill (NRVB, Nirex Reference Vault Backfill). In contrast, the solubility of U(VI) was one order of magnitude higher in $\mathrm{NaOH}$ than in the remaining solutions. The presence of cellulose degradation products (CDP) results in a comparable solubility increase for both elements. Extended X-ray Absorption Fine Structure (EXAFS) data suggest that the solubility-limiting phase for uranium corresponds to a becquerelite-type solid whereas thermodynamic modelling predicts a poorly crystalline, hydrated calcium uranate phase. The solubility-limiting phase for thorium was $\mathrm{ThO}_{2}$ of intermediate crystallinity. No breakthrough of either uranium or thorium was
\end{abstract}


observed in diffusion experiments involving NRVB after three years. Nevertheless, backscattering electron microscopy and microfocus X-ray fluorescence confirmed that uranium had penetrated about $40 \mu \mathrm{m}$ into the cement, implying active diffusion governed by slow dissolution-precipitation kinetics. Precise identification of the uranium solid proved difficult, displaying characteristics of both calcium uranate and becquerelite.

Keywords: uranium, thorium, solubility, through-diffusion, cement. 


\section{Introduction}

Cement is used widely for the stabilisation of hazardous materials owing to its capacity for both physical and chemical immobilisation of contaminant species (Wilk, 2004; Jantzen et al., 2010). The present concept for the disposal of intermediate level (ILW) and some longlived low level (LLW) radioactive waste in the UK is based on grouting the waste in stainless steel canisters, placing the containers in a geological disposal facility (GDF) deep underground and backfilling with a bespoke cement matrix such as Nirex Reference Vault Backfill (NRVB, Francis et al., 1997). In this multi-layered system, the cement acts not only as a physical barrier to migration but also contributes to the chemical containment of waste components by buffering the groundwater to a high $\mathrm{pH}$, whereby the solubility of many radionuclides is limited (Francis et al., 1997). Unlike other cementitious materials being considered as backfill for a GDF, the NRVB is designed to have low strength, allowing package retrieval after backfilling of the repository vaults. Bamforth et al. (2012) have carried out an extensive review of the physical and chemical characteristics of NRVB and compared it with other cementitious backfill materials available worldwide, finding certain similarities between the performance of NRVB and mortars considered in the Swiss GDF concept.

One of the characteristics of the LLW and ILW inventory in the UK is the presence of cellulose residues, which degrade under alkaline conditions to give a complex mixture of carboxylated compounds (Humphreys et al., 2010), known collectively as cellulose degradation products (CDP). These compounds have the potential to inhibit the retardation of radionuclides, either by increasing their solubility or by modifying the reactive surface responsible for the adsorption of the radionuclides (Baston et al., 2012).

Numerous examples can be found in the literature regarding the solubility under hyperalkaline conditions of U(IV) (Baston et al., 1993; Fujiwara et al., 2005), U(VI) (Ewart et al., 
1992; Yamamura et al., 1998; Sutton et al., 1999; Fujiwara et al., 2005; King et al., 2008; Colàs et al., 2013a) and Th (Ewart et al., 1992; Thomasson and Williams, 1992; Wierczinski et al., 1998; Neck et al., 2002, 2003; Brendebach et al., 2007; Colàs et al., 2011, 2013b; Kitamura et al., 2013). Most studies on thorium focus on colloid generation phenomena (Fanghänel and Neck, 2002) given its low solubility and tendency to hydrolyse (Walther et al., 2008; Priyadarshini et al., 2016). Less attention has been paid to thorium adsorption (Wierczinski et al., 1998; Tits et al., 2000, 2005; Cowper et al., 2006; Felipe-Sotelo et al., 2012) or incorporation into cement phases.

Rothe et al. (2013) and Bube et al. (2014) characterised U(VI) phases in doped ordinary Portland cement (OPC): X-ray Absorption Near-Edge Structure ( $\mu$-XANES) and Raman spectroscopy indicated that the uranium solids formed were similar to diuranates $\left(\mathrm{CaU}_{2} \mathrm{O}_{7} / \mathrm{Na}_{2} \mathrm{U}_{2} \mathrm{O}_{7} \cdot \mathrm{xH}_{2} \mathrm{O}\right)$. The phases were largely amorphous; some localised formation of a uranophane-like $\left(\mathrm{Ca}\left(\mathrm{UO}_{2}\right)_{2}\left(\mathrm{SiO}_{3} \mathrm{OH}\right)_{2} \cdot 5 \mathrm{H}_{2} \mathrm{O}\right)$ phase suggesting meta-stability and that the transition to more thermodynamically stable mineral silicates is kinetically hindered. On the basis of EXAFS results, Wieland et al. (2010) suggested that U(VI) in cement pastes presents a coordination environment comparable to uranophane. Similar structural parameters were observed for U(VI) uptake by calcium silicate hydrate (CSH; Harfouche et al., 2006).

The above studies illustrate the difficulty in identifying uranium-containing phases in Portland cements. In the present work, a series of solubility experiments was carried out in alkaline solutions of increasing complexity, from $\mathrm{NaOH}$, through $\mathrm{Ca}(\mathrm{OH})_{2}$ and NRVBequilibrated waters to solutions containing CDP. The solubility values were compared to those predicted by thermodynamic modelling using the JCHESS code (van der Lee, 1998) and published data (HATCHES, version 20, http://www.hatches-database.com). Diffusion experiments were also carried out using NRVB monoliths, with and without CDP. Identification of the solid phases responsible for retardation was attempted using EXAFS and 
complementary microscopic techniques. The main motivation for the work is to generate a consistent body of experimental data that provides confidence in the concept of chemical containment for the disposal of radioactive waste. The experiments include solubility determinations in a variety of alkaline solutions together with batch sorption, throughdiffusion and advection tests over extended periods of time, from several months to four years. The work forms part of a wider programme that, to date, has investigated adsorption (Felipe-Sotelo et al., 2012) and the mobility under near field conditions of $\mathrm{Cl}^{-}$(van Es et al., 2015), I', $\mathrm{Cs}^{+}$,(Felipe-Sotelo et al., 2014), $\mathrm{Ni}^{2+}$ (Felipe-Sotelo et al., 2016a) and $\mathrm{SeO}_{3}{ }^{2-}$ (Felipe-Sotelo et al., 2016b).

\section{Experimental}

\subsection{Solubility experiments}

The solubility of uranium and thorium was assessed in six different media to represent analogue chemical conditions to those expected in the near field of a cementitious repository. Solubility measurements were approached from both the over- and under-saturation directions. The aqueous media tested were $0.02 \mathrm{M} \mathrm{NaOH}, 95 \%$-saturated $\mathrm{Ca}(\mathrm{OH})_{2}, \mathrm{NRVB}$ equilibrated water and CDP generated in the presence of NRVB. The NRVB was prepared according to the NDA specification (Nuclear Decommissioning Authority, 2010), containing 0.26 fraction weight OPC, 0.29 of limestone flour, 0.1 of hydrated lime and 0.35 water. Full details can be found elsewhere regarding the preparation of $0.02 \mathrm{M} \mathrm{NaOH}$ and $95 \%$-saturated $\mathrm{Ca}(\mathrm{OH})_{2}$ (Felipe-Sotelo et al., 2016a), and the NRVB and CDP solutions (Felipe-Sotelo et al., 2014). The composition of the solutions is provided in Table 1. Table 2 shows the evolution of the $\mathrm{pH}$ and $\mathrm{E}_{\mathrm{h}}$ values over the whole duration of the solubility experiments, for both the over- and under-saturation directions. 
Additional experiments were carried out in which reducing agents were added to the CDP solutions; either sodium dithionite $\left(\mathrm{Na}_{2} \mathrm{~S}_{2} \mathrm{O}_{4}\right)$ or solid iron. In both cases, after filtration, the CDP solution was left to equilibrate with iron fillings (1g/L, Alfa Aesar®) for 72 hours under $\mathrm{N}_{2}$-atmosphere. After filtration of the Fe fillings, $0.03 \mathrm{M} \mathrm{Na} \mathrm{S}_{2} \mathrm{O}_{4}$ (ca. 85\% tech., Acrös Organics) was added to a fraction of the CDP batch. All the solutions employed in the solubility experiments were subjected to ultrafiltration $(30 \mathrm{kDa}$ regenerated cellulose membranes, Millipore Amicon® Bioseparations) before addition of the radionuclides. $100 \mathrm{~mL}$ aliquots of the solutions were then transferred to Teflon® containers.

For experiments using CDP with Fe, two strips of $\mathrm{Fe}(90 \mathrm{~mm} \times 15 \mathrm{~mm} \times 0.5 \mathrm{~mm}$, Fisher Scientific) were attached to the caps of the Teflon ${ }^{\circledR}$ containers so that $60 \mathrm{~mm}$ of the metal remained submerged in the CDP solution. For the over-saturation experiments, the solutions were spiked with $0.2 \mathrm{M}$ solutions of $\mathrm{Th}\left(\mathrm{NO}_{3}\right)_{4}$ (thorium nitrate hydrate puriss. 99\%, Fluka) and $\mathrm{UO}_{2}\left(\mathrm{NO}_{3}\right)_{2}\left(\mathrm{UO}_{2}\left(\mathrm{NO}_{3}\right)_{2} \cdot 6 \mathrm{H}_{2} \mathrm{O}\right.$, TAAB) in deionised water in order to provide a total inventory of $10^{-4} \mathrm{~mol}$ of either uranium or thorium. The same total inventory was added in the under-saturation experiments but, in this case, the radionuclides were added as a slurry. The precipitates were generated in each of the aqueous media tested by addition of either $10^{-4} \mathrm{~mol}$ $\mathrm{Th}\left(\mathrm{NO}_{3}\right)_{4}$ or $\mathrm{UO}_{2}\left(\mathrm{NO}_{3}\right)_{2}$ to $15 \mathrm{~mL}$ of each of the solutions. It should be noted that during this preparatory step, the concentrations of Th and $\mathrm{U}$ were almost equimolar with the levels of $\mathrm{Na}$ and/or Ca in the solutions (see concentrations in Table 1). The resulting precipitates were left to age in contact with the supernatant for 28 days, after which they were centrifuged and the supernatant removed; the resulting pellets were transferred to the Teflon ${ }^{\circledR}$ containers with the tests solutions. Characterisation of the precipitates was attempted by powder X-ray diffraction (XRD); however, the materials were amorphous and did not show any recognisable diffraction pattern (Figure S1 in Supplementary Information). Ten replicates were prepared for each aqueous medium and saturation direction. All the solubility 
experiments were prepared and kept in a glove-box under $\mathrm{N}_{2}$-atmosphere for the whole duration of the assays (1340 days). The concentrations of $U$ and Th were measured in the supernatant by inductively coupled plasma mass spectrometry (ICP-MS); $1 \mathrm{~mL}$ samples were filtered with pre-conditioned 0.2 $\mu \mathrm{m}$ PES filters (Jaytee Biosciences Ltd) and acidified with $\mathrm{HNO}_{3}$ (TraceSELECT®Ultra, Fluka), resulting in a final acid concentration of $2 \% \mathrm{v} / \mathrm{v}$. The ICP-MS (Agilent, 7700x Series) was tuned and calibrated on a daily basis with traceable U and Th standards, using $\mathrm{Bi}$ as internal standard (Assurance, Spexcertiprep). The limits of detection (LOD, $3 \sigma$ ) were $4.1 \times 10^{-10}$ and $4.9 \times 10^{-10} \mathrm{M}$ for $\mathrm{U}$ and $\mathrm{Th}$, respectively.

\subsection{Through-diffusion experiments}

The diffusion of uranium and thorium was assessed using a radial diffusion configuration (Markovaara-Koivisto et al., 2009) successfully adapted for the diffusion of $\mathrm{Cs}^{+}$, I- (FelipeSotelo et al., 2014) and $\mathrm{Cl}^{-}$(van Es et al., 2015) through NRVB. The samples consisted of cylinders of cured NRVB with a central well where spikes containing either $U$ or Th could be added. Full details regarding the preparation, curing and dimensions of the NRVB blocks are provided elsewhere (Felipe-Sotelo et al., 2014). Two sets of experiments were carried out; in NRVB-equilibrated water and in the CDP solution. Uranium and thorium slurries were produced by addition of a solution of either $\mathrm{UO}_{2}\left(\mathrm{NO}_{3}\right)_{2}$ or $\mathrm{Th}\left(\mathrm{NO}_{3}\right)_{4}$ to $0.5 \mathrm{M} \mathrm{NaOH}$, followed by centrifugation, removal of the supernatant solution and re-suspension in either cement-equilibrated water or CDP solution. After placing the slurry in the central well of the NRVB cylinders, they were sealed, submerged in the appropriate solution and kept under $\mathrm{N}_{2-}$ atmosphere for total period of 976 days. The total inventory of $U$ and Th added to the NRVB blocks was $2.5 \times 10^{-4}$ mol. Breakthrough was monitored by analysing the solution surrounding the cylinders by ICP-MS. The samples were not replaced with fresh solution. 


\subsection{Solid characterisation}

In order to investigate the nature and evolution of the solid phases formed in the solubility experiments, the samples were centrifuged and the supernatant removed, after which $1 \mathrm{~mL}$ of acetone (HPLC grade, Fisher Scientific) was added to the precipitates followed by further centrifugation. After removal of the organic solvent, the solids were left to dry under $\mathrm{N}_{2}$ atmosphere. The Fe coupons were removed from solution and gently washed with a small amount of acetone and then left to dry in the glove-box. Before EXAFS analysis the samples were ground using an agate pestle and mortar and mixed with cellulose to yield a concentration of approximately $2000 \mathrm{ppm}$. Approximately $40 \mathrm{mg}$ of the sample were then placed into a Perspex sample holder, sealed with three layers of Kapton ${ }^{\circledR}$ tape. The sample holder was then heat sealed under a nitrogen atmosphere to prevent oxidation of the samples during their transport and measurement.

The EXAFS measurements were performed at the B18 experimental station at the Diamond Light Source (Dent et al., 2009). The energy of the beam was calibrated against the K-edge first derivative of a Y foil, defined at $17,038 \mathrm{eV}$. Measurements were conducted at the U LIIIedge in fluorescence mode using a nine element Ge detector mounted perpendicular to the incoming beam. The sealed samples were positioned at $45^{\circ}$ relative to the incoming X-ray beam. The EXAFS spectra were corrected for remaining self-absorption using the Fluo algorithm in Athena 0.9.18 (Newville et al., 1995). EXAFS w(k) values were refined from the raw data by standard procedures, including background subtraction, normalization of absorption and conversion to momentum and $\mathrm{k}$ space. For each sample $\sim 34$ spectra were averaged to improve the signal-to-noise ratio. The spectra were then analysed with Artemis 0.9.18 and the phase/amplitude functions were calculated by FEFF6L (Newville et al., 1995). The theoretical fits were performed in R-space. 
The sectioned NRVB cores from the diffusion experiments were examined uncoated under variable pressure conditions using both backscatter scanning electron microscopy (BSEM) and large field detection (LFD). Prior to BSEM- energy-dispersive X-ray analysis (EDXA), the samples were coated with a thin layer $(25 \mathrm{~nm})$ of carbon under vacuum using an EMITECH 960L evaporation coating unit. EDXA data were acquired and processed using the Oxford Energy INCA Suite Version 5.04 Issue 21a+SP2 (2012) software. All imaging was carried out using a FEI Company QUANTA 600 environmental scanning electron microscope (ESEM) equipped with an Oxford Instruments INCA EDXA system and a $50 \mathrm{~mm}^{2}$ Peltier-cooled silicon drift detector (SSD) X-ray detector.

For X-ray fluorescence mapping, the cores were dissected further to yield a wedge approximately $1 \mathrm{~cm}$ in thickness and with an area of $3 \mathrm{~cm}^{2} . \mathrm{X}$-ray fluorescence mapping was performed at the I18 station at the Diamond Light Source. The samples were analysed for uranium, calcium and iron using a beam size of $3 \mu \mathrm{m}$. Data were collected using a 9 element solid state detector. The resulting maps were analysed using the freely available software package, PyMCA. Precipitates removed from the central well of the diffusion cylinders were also analysed by EXAFS, as above.

\section{Results}

\subsection{Concentrations of $U$ and $T h$ in solution}

The solubility results obtained here are summarised in Tables 3, 4 and 5 for U(VI), UIV) and Th, respectively, where they can be compared with literature values. Significant differences were observed between uranium concentrations in the over- and under-saturation experiments (Figures 1a, 2 and 3). The sole exception to this trend was found in the CDP solution containing $0.03 \mathrm{M} \mathrm{Na}_{2} \mathrm{~S}_{2} \mathrm{O}_{4}$ (Figure 3c), where both saturation directions gave similar results; however, the results began to diverge beyond 200 days. 
In the absence of $\mathrm{CDP}, \mathrm{NaOH}$ exhibited the highest concentration of $\mathrm{U}$ in solution. Experiments in $95 \%$-saturated $\mathrm{Ca}(\mathrm{OH})_{2}$ and $\mathrm{NRVB}$-equilibrated water gave solubility values approximately one order of magnitude lower and follow similar trends (Figure 1a). For the over-saturation experiments, $\mathrm{U}$ concentrations decrease markedly over the first 28 days and then more gradually before stabilising after approx. 250 days (Figure 2). The trend is less clear in the under-saturation experiments; nevertheless, the CDP increased the solubility of uranium in all cases (Figure 3). Initial concentrations of $U$ in solution for the over-saturation tests were around $10^{-5} \mathrm{M}$, followed by a decrease of one order of magnitude over a period of 100-200 days. The Fe coupons had no significant impact on U solubility (Figure 3c). However, $0.03 \mathrm{M} \mathrm{Na} 2 \mathrm{~S}_{2} \mathrm{O}_{4}$ was effective in reducing U(VI) to U(IV) and this counteracts the solubilising influence of the CDP (Figure 1a).

The average concentrations of thorium measured in $0.02 \mathrm{M} \mathrm{NaOH}, 95 \%$-saturated $\mathrm{Ca}(\mathrm{OH})_{2}$ and NRVB-equilibrated water overlap for both the over- and under-saturation experiments (Figure 4). Solubility increases by approximately one order of magnitude in the presence of CDP (Figure 5).

\subsection{Solid phase characterisation}

A subset of precipitates from the over-saturation solubility experiments was subjected to EXAFS analysis in order to identify the solubility-limiting phases for uranium. EXAFS spectra and corresponding Fourier transforms with modelled data are shown in Figure 6.

The best fit for the uranium precipitates formed in the presence of elemental iron indicates that the uranium is in the (VI) oxidation state, with two axial oxygen at $1.8 \AA$ and five equatorial oxygen atoms at distances between 2.32 and $2.42 \AA$. In order to improve the fit, it was necessary to consider the presence of a second shell of four uranium atoms at between 3.70 and $3.83 \AA$. The fit was further improved by adding a path for a single calcium atom at a 
distance of $4.09 \AA$. The coordination numbers and bond distances are consistent with a U(VI) oxy-hydroxide such as becquerelite $\left(\mathrm{Ca}\left(\mathrm{UO}_{2}\right)_{6} \mathrm{O}_{4}(\mathrm{OH})_{6} \cdot 8 \mathrm{H}_{2} \mathrm{O}\right)$. Thus, the scattering paths and coordination numbers taken from becquerelite crystallographic data (Pagoaga et al., 1997) were used to fit the EXAFS data.

In the case of uranium precipitates generated in CDP and $0.03 \mathrm{M} \mathrm{Na} \mathrm{Na}_{2} \mathrm{O}_{4}$, there is a noticeable shift of the absorption edge to the left, indicating partial reduction of the uranium to U(IV). The EXAFS results were fitted using becquerelite crystallographic data; however, it was necessary to add a single scattering path from uraninite $\left(\mathrm{UO}_{2}\right)$ at $2.37 \AA$ to adequately describe the data. All fitting parameters for both precipitates are shown in Table 6.

\subsection{Through-diffusion experiments}

No breakthrough of uranium through NRVB was observed in the radial diffusion experiments after 976 days. Therefore, two replicates were sacrificed, one with and one without CDP, in order to determine the extent of diffusion. BSEM images (Figure S2 in Supplementary Information, SI) show that, in the absence of CDP, the U(VI) precipitates do not penetrate into the cement matrix but that when CDP are present, discrete areas of higher uranium concentration can be found in the NRVB cylinder to a depth of approximately $40 \mu \mathrm{m}$ (Figure 7).

Samples of the precipitate were removed from the central well and compositional data collected by EDXA. The resulting data gave average $\mathrm{Si} C \mathrm{Ca}: \mathrm{U}: \mathrm{O}$ atomic ratios of 0.1:0.9:1:4, which match closely with the composition of calcium uranate $\left(\mathrm{CaUO}_{4}\right)$. The presence of minor silicon may indicate incipient formation of a uranyl silicate, such as uranophane, but equally could be due to the overlapping of an unresolved microcrystalline cementitious phase. The presence of CDP does not lead to any discernible change in mineral composition. 
In contrast, EXAFS spectra for these precipitates were tentatively identified as U(VI) oxyhydroxides as the data show a good fit to the co-ordination numbers and scattering paths from becquerelite (Table 7).

The concentrations of thorium in solution were below the LOD for the through-diffusion experiments with or without CDP after three years in either of the diffusion experiments and therefore, two replicates were sectioned to examine the diffusion profiles. BSEM images of Th-rich precipitates collected from the central well of the cylinder used for diffusion in the absence of CDP, show a thick $(\sim 100 \mu \mathrm{m})$ gel coating the wall (Figure S3a) above a layer of dendritic deposits (Figure S3b), whereas in the presence of CDP, the precipitate appears as acicular crystals (Figure S4). Backscattering images of the edge of the well and EDXA elemental mapping across the boundary area show high concentrations of thorium within the well but no indication of diffusion into the cement matrix. There is a negative correlation with $\mathrm{Ca}$ and no apparent relationship to either silicon or iron (Figure S5a).In the experiment with CDP, the Th-rich coating is much thinner at $\sim 10 \mu \mathrm{m}$. Again, elemental mapping suggests insignificant diffusion of Th into the NRVB (Figure $\mathbf{S 4 b}$ ).

\section{Discussion}

\subsection{Solubility}

\subsubsection{Concentrations of $U$ and $T h$ in solution}

When comparing the $E_{h}$ values presented in Table 2 for the solutions used in the solubility studies with the redox evolution profiles modelled by Grivé et al. (2011), the $0.02 \mathrm{M} \mathrm{NaOH}$, 95\%-saturated $\mathrm{Ca}(\mathrm{OH})_{2}$, NRVB water and $\mathrm{CDP}$ solutions may be considered to represent the conditions expected in the GDF during the third stage of redox evolution, between 160 and 200 years after closure. On this timescale, the backfill material, i.e. NRVB, would be changing from oxic to anoxic conditions whereas the waste will already be anoxic. Under 
such conditions in the backfill, the dominant uranium species would be U(VI) (Salah and Wang, 2014). The CDP $+\mathrm{Na}_{2} \mathrm{~S}_{2} \mathrm{O}_{4}$ solution would represent a point further along this transient stage; however, the redox potential in the NRVB would not achieve steady state at around $-800 \mathrm{mV}$ until well beyond 200 years (Grivé et al., 2011) and thus, both oxidation states of uranium, U(VI) and U(IV) may coexist (Salah and Wang, 2014).

The results obtained in the present study indicate that in the absence of CDP, uranium reaches its highest solubility in $0.02 \mathrm{M} \mathrm{NaOH}$. Although the solubility of $\mathrm{U}$ showed a marked reduction over the first 28 days of the experiments, it did not reach the levels attained in either saturated $\mathrm{Ca}(\mathrm{OH})_{2}$ or NRVB solutions. Fanghänel and Neck (2002) attributed the reduction in solubility observed for $\mathrm{U}(\mathrm{VI})$ in $\mathrm{NaOH}$ to changes in the solubility controlling phase and transformation of $\mathrm{UO}_{3} \cdot 2 \mathrm{H}_{2} \mathrm{O}_{(\mathrm{s})}$ to $\mathrm{Na}_{2} \mathrm{U}_{2} \mathrm{O}_{7} \cdot \mathrm{xH}_{2} \mathrm{O}_{(\mathrm{s})}$.

Overall, values obtained for the solubility of U(VI) from the under-saturation direction are lower than concentrations reported under similar experimental conditions elsewhere (Table 3). The final concentration of $\mathrm{U}$ in $0.02 \mathrm{M} \mathrm{NaOH}$ was $5.8 \times 10^{-8} \mathrm{M}$; three orders of magnitude below that reported by Gayer and Leider (1955), who obtained $(4.45-7.9) \times 10^{-5} \mathrm{~mol} / \mathrm{kg}$. These authors studied the dissolution of $\mathrm{UO}_{3} \cdot \mathrm{H}_{2} \mathrm{O}$, which is not crystallographically identical to the phase formed here. The solubility of $\mathrm{U}(\mathrm{VI})$ in $95 \%$-saturated $\mathrm{Ca}(\mathrm{OH})_{2}\left(5.2 \times 10^{-9} \mathrm{M}\right)$ is also significantly lower than the value obtained by Valsami-Jones and Ragnarsdóttir (1997) for microcrystalline $\mathrm{UO}_{3}\left(5 \times 10^{-7} \mathrm{M}\right)$ and $\mathrm{CaU}_{1.6} \mathrm{O}_{5.8} \cdot \mathrm{H}_{2} \mathrm{O}\left(8 \times 10^{-7} \mathrm{M}\right)$.

The final concentrations of $U$ from the over-saturation direction were $1.9 \times 10^{-6} \mathrm{M}$ and $6.4 \times 10^{-8}$ $\mathrm{M}$ in $0.02 \mathrm{M} \mathrm{NaOH}$ and $95 \%$-saturated $\mathrm{Ca}(\mathrm{OH})_{2}$, respectively. These results fit well with the data of Clacher and Cowper (2011) who reported concentrations ranging from $1.5 \times 10^{-7}$ to $9.3 \times 10^{-5} \mathrm{M}$ in $0.01 \mathrm{M} \mathrm{NaOH}(\mathrm{pH}=12-11.6)$ and from $7.0 \times 10^{-8}$ to $3.0 \times 10^{-7} \mathrm{M}$ in near-saturated $\mathrm{Ca}(\mathrm{OH})_{2}(\mathrm{pH}=12$ - 11.2) (Table 3). 
The average concentrations of $\mathrm{U}(\mathrm{VI})$ in the NRVB-equilibrated water were $7.3 \pm 3.8 \times 10^{-8} \mathrm{M}$ and $4.6 \pm 3.6 \times 10^{-9} \mathrm{M}$ for the over- and under-saturation experiments, respectively. These values are very similar to the data for $\mathrm{Ca}(\mathrm{OH})_{2}$, suggesting that portlandite plays a major role in NRVB solution chemistry. Uranium solubilities 2-4 orders of magnitude higher have been reported in earlier over-saturation experiments in cement-equilibrated water: Ewart et al. (1992) and Baston et al. (1993) obtained U(VI) $\approx 5 \times 10^{-6} \mathrm{M}$ at $\mathrm{pH} 12$ and $2 \times 10^{-5} \mathrm{M}$ at $\mathrm{pH} 13$. These authors used ordinary Portland cement:Blast Furnace Slag (OPC:BFS) at a ratio of 1:9 and shorter equilibration times (maximum 60 days); consequently the two systems are not directly comparable.

Uranium solubility determined in the presence of CDP is similar to previous results obtained by Baston et al. (1993) for OPC:BFS cement waters and by Greenfield et al. (1997) in an NRVB equilibrated solution (Tables 3 and 4). Higher solubility values quoted by Greenfield et al. (1997) reflect CDP with $10 \%$ cellulose loading compared to the $5 \%$ w/w loading in the present study.

The solubilities obtained in the present work in the CDP $+0.03 \mathrm{M} \mathrm{Na} \mathrm{S}_{2} \mathrm{O}_{4}$ solutions are similar (Table 4) to the values reported previously in cement equilibrated waters, such as NRVB (Greenfield et al, 1997) and BFS:OPC (Baston et al., 1993) in the absence of any organic ligands. Therefore, it could be suggested that either CDP do not significantly increase the solubility of U(IV) or equally, it could pose the question as to whether the values reported by Baston et al. (1993) and Greenfield et al. (1997) might actually correspond to a mixture of $\mathrm{U}(\mathrm{IV})$ and $\mathrm{U}(\mathrm{VI})$. As can be seen in Table 2, the $\mathrm{E}_{\mathrm{h}}$ of the $\mathrm{CDP}+0.03 \mathrm{M} \mathrm{Na} \mathrm{S}_{2} \mathrm{O}_{4}$ solution changed from approx. $-560 \mathrm{mV}$ to around $-300 \mathrm{mV}$ (against SHE) at the end of the experiments (1340 days). This drift in the redox potential could explain the increase in solubility observed for these experiments after 200 days (Figure 3c), which also ties in with 
EXAFS results for the precipitates, which show only partial reduction of U(VI) (becquerelite) into U(IV) (uraninite).

The final concentrations obtained for thorium after 1340 days equilibration are listed together with literature values in Table 5. Thorium solubility in $\mathrm{NaOH}$ ranged between $2.1 \times 10^{-10}$ and 3.7 $\times 10^{-8} \mathrm{M}$, which compares with the values reported by Neck et al. (2002) for the same solution $\left(1.8 \times 10^{-9}-6.8 \times 10^{-7} \mathrm{M}\right)$. The average concentration for Th in NRVB-equilibrated water over the whole experimental period was $(4 \pm 6) \times 10^{-9} \mathrm{M}$ for both over- and undersaturation experiments; this compares well with values reported by Ewart et al. (1992), $\sim 4 \times 10^{-9} \mathrm{M}$ in OPC:BFS and OPC:limestone equilibrated waters ( $\mathrm{pH} 12$ ). Kitamura et al. (2013) obtained $7 \times 10^{-10}$ to $2 \times 10^{-8} \mathrm{M}$ in squeezed OPC pore water at $\mathrm{pH} 13.5$. Wierczinski et al. (1998) measured the solubility of microcrystalline $\mathrm{ThO}_{2}$ in fresh $(\mathrm{pH} 13.22)$ and aged cement-equilibrated water ( $\mathrm{pH} 12.45$ ), obtaining $[\mathrm{Th}] \approx 10^{-9} \mathrm{M}$ and $\approx 10^{-10} \mathrm{M}$, respectively. Brendebach et al. (2007) and Altmaier et al. (2008) reported significant increases in Th solubility to $\sim 10^{-7}-10^{-3} \mathrm{M}$ at $\mathrm{pH} 11-12$ with $\mathrm{CaCl}_{2}$ owing to formation of $\mathrm{Ca}_{4}\left[\mathrm{Th}(\mathrm{OH})_{8}\right]^{4+}$ as identified by EXAFS. A similar increase was not apparent here as there is little difference between the solubility of Th in $\mathrm{NaOH}, \mathrm{Ca}(\mathrm{OH})_{2}$ or NRVB solutions. It should be noted that the concentrations of Ca employed by Brendebach et al. (2007) and Altmaier et al. (2008) were up to two orders of magnitude higher than those considered here $([\mathrm{Ca}] \approx 0.01 \mathrm{M})$. Colàs et al (2011) reported that at concentrations of gluconate (an analogue of ISA) around $2 \times 10^{-2} \mathrm{M}$ and at $\mathrm{pH} \mathrm{12,} \mathrm{there} \mathrm{was} \mathrm{significant} \mathrm{adsorption} \mathrm{of} \mathrm{the} \mathrm{organic} \mathrm{ligand} \mathrm{to} \mathrm{the} \mathrm{surface} \mathrm{of} \mathrm{the} \mathrm{Th}$ solid phase $\left(\mathrm{ThO}_{2} \cdot \mathrm{xH}_{2} \mathrm{O}_{(\mathrm{am})}\right)$, which prevented its dissolution; this led to measured values of Th in under-saturation conditions one order of magnitude lower than the values obtained by over-saturation. The final Th concentrations measured in the CDP solutions in the present work after 1340 days equilibration were also lower for under-saturation $\left(2.3 \times 10^{-9} \mathrm{M}\right)$ than for over-saturation $\left(7.3 \times 10^{-8} \mathrm{M}\right)$ (Table 5); however, due to the high variability of the data 
observed over the experimental period (Figure 5) and the lower concentration of organics (equivalent to $2.6 \times 10^{-3} \mathrm{M}$ ISA), the conclusions from Colàs et al (2011) may not be directly applicable to this study.

\subsubsection{Modelling predictions}

As the formation of highly crystalline phases may be expected only at elevated temperatures and, given the fact that analysis of the solubility controlling phases by powder XRD indicates very poor crystallinity, the modelling results presented here have only considered the formation of amorphous hydrated solids. An overview of the reactions and stability constants used for the calculations in the present study can be found in Table S1 of the Supplementary Information. For uranium in $0.02 \mathrm{M} \mathrm{NaOH}$ the predicted solubility is $(2.3-5.9) \times 10^{-6}$, which is in good agreement with the experiments; the equilibrium solubility calculations only allowed for the presence of poorly crystalline $\mathrm{Na}_{2} \mathrm{U}_{2} \mathrm{O}_{7}$ or $\mathrm{NaUO}_{2}(\mathrm{OH})_{3(\mathrm{~s})}$ with $\log \mathrm{K}_{\mathrm{sp}}=25.1$ as reported by Yamamura et al. (1998). However, the thermodynamic equilibrium models overestimate the solubility obtained for the under-saturation experiments, irrespective of whether constants for $\mathrm{Na}_{2} \mathrm{U}_{2} \mathrm{O}_{7(\text { hydr) }}$ or $\mathrm{Na}_{2} \mathrm{U}_{2} \mathrm{O}_{7 \text { (cr) }}$ are considered (Figure 2a).

For both the $\mathrm{Ca}(\mathrm{OH})_{2}$ and NRVB systems, the thermodynamic equilibrium models were constructed considering the precipitation of $\mathrm{CaUO}_{4}$ with $\log \mathrm{K}_{\mathrm{sp}}=23.1$, as reported by Moroni and Glasser (1995), which results in calculated solubility values of $(4-9) \times 10^{-7} \mathrm{M}$ $\mathrm{U}(\mathrm{VI})$, similar to the experimental results (Figures $\mathbf{2 b}$ and $\mathbf{c 2}$ ).

For the calculation of uranium solubility in the CDP solutions, the concentrations of the four compounds identified in the cellulose degradation mixture, namely isosaccharinic (ISA), lactic, formic and acetic acids (Table 1), were inserted in the thermodynamic models. In the presence of CDP and without reducing agents, the main species in predicted in solution is $\mathrm{UO}_{2} \mathrm{ISA}^{3-}\left(\log \mathrm{K}=-36.5\right.$ for the formation reaction from $\mathrm{U}^{4+}$ and $\mathrm{H}_{4} \mathrm{ISA}^{-}$, calculated by Baston 
et al. (2008) with experimental data from Greenfield et al. (1997)). With the solubility product for $\mathrm{CaUO}_{4}$ reported by Moroni and Glasser (1995), the calculated concentrations of $\mathrm{U}$ approximate the values obtained experimentally $\left((1-2) \times 10^{-6} \mathrm{M}\right.$ for over-saturation; Figures 3a,c). The equilibrium solubility calculations indicate no significant reduction of $\mathrm{U}(\mathrm{VI})$ to $\mathrm{U}(\mathrm{IV})$ in the presence of Fe coupons at $\mathrm{E}_{\mathrm{h}}$ values between -21 and $-13 \mathrm{mV}$ (against standard hydrogen electrode, SHE, Table 2), as observed experimentally. With the addition of $0.03 \mathrm{M} \mathrm{Na} \mathrm{S}_{2} \mathrm{O}_{4}$, the thermodynamic equilibrium model predicts the formation of solid $\mathrm{UO}_{2}$ and $\mathrm{UISA}^{-}$as the main species in solution (log $\mathrm{K}=-5.94$ as reported Baston et al. (2008) with data from Greenfield et al. (1997)). Allowing only for precipitation of $\mathrm{UO}_{2(\mathrm{am})}$, the equilibrium solubility calculations predicted aqueous concentrations of U(IV) in the range of (4 - 6) $\times 10^{-7} \mathrm{M}$, in good agreement with the solubility obtained in the over-saturation experiments (Figure 3b), with similar molar contributions from $\mathrm{U}(\mathrm{OH})_{4(\mathrm{aq})}$ and $\mathrm{UISA}^{-}$to the total U concentration.

In broad terms, consideration of amorphous solubility-controlling phases allowed satisfactory prediction of $\mathrm{U}$ concentrations in all six of the aqueous media investigated. Systematic overestimation of the concentration in solution for experiments carried out from the undersaturation direction suggests that the solid phases produced exhibit an intermediate crystallinity between purely crystalline and amorphous $\mathrm{Na}_{2} \mathrm{U}_{2} \mathrm{O}_{7}$ (in $\mathrm{NaOH}$ ), $\mathrm{CaUO}_{4}$ (in $\mathrm{Ca}(\mathrm{OH})_{2}, \mathrm{NRVB}$ and $\left.\mathrm{CDP}\right)$ or $\mathrm{UO}_{2}\left(\mathrm{CDP}+\mathrm{Na}_{2} \mathrm{~S}_{2} \mathrm{O}_{4}\right)$. Another potential explanation for the differences observed between the over - and under-saturation results may be related to differences in the $\mathrm{Ca}$ and $\mathrm{Na}$ inventories available for precipitation of the uranium salts in the two experiments as indicated in section 2.1, which may have led to changes in the stoichiometry of the solid phases. However, characterisation of the solids by EXAFS raises the possibility that becquerelite may be the solubility-controlling phase in Ca-rich systems. With an average $\log \mathrm{K}_{\mathrm{sp}}=42.45$ calculated from published solubility products (Vochtem and 
van Haverbeke, 1990; Sandino and Grambow, 1994; Rai et al., 2002), precipitation of becquerelite is not predicted and the $\mathrm{U}$ concentration in solution corresponds to the total inventory $\left(10^{-3} \mathrm{M}\right)$. Casas et al. (1997) reported a lower solubility product for becquerelite $\left(\log \mathrm{K}_{\mathrm{sp}}=29 \pm 1\right)$. Taking this value, the $\mathrm{U}$ concentration predicted in the NRVB solution is $6.5 \times 10^{-7} \mathrm{M}$. This result tallies better with measured data but nevertheless, still overestimates solubility.

Initial calculations of thorium solubility gave a predicted concentration of $2.2 \times 10^{-16} \mathrm{M}$, controlled by thorianite $\left(\mathrm{ThO}_{2}\right)$; some $7-8$ orders of magnitude below the values obtained experimentally. Fanghänel and Neck (2002) speculated that the very large variability in reported solubility values for Th, as well as widespread discrepancies between experimental and thermodynamic modelling results, could be due to control of experimental conditions, leading to a variety of oxy-hydroxides displaying different degrees of hydration $\left(\mathrm{ThO}_{\mathrm{n}}(\mathrm{OH})_{4-2 \mathrm{n}(\mathrm{am})}\right)$. The difference in solubility between crystalline $\mathrm{ThO}_{2}\left(\log \mathrm{K}_{\mathrm{sp}}=-54.2 \pm\right.$ 1.3), microcrystalline $\mathrm{ThO}_{2}\left(\log \mathrm{K}_{\mathrm{sp}}=-53.2 \pm 0.4\right)$ and $\mathrm{ThO}_{2(\mathrm{am}, \mathrm{hyd})}$ or $\mathrm{Th}(\mathrm{OH})_{4(\mathrm{am})}\left(\log \mathrm{K}_{\mathrm{sp}}=-\right.$ $47.8 \pm 0.3$ ) could be explained on the basis of the particle size and incomplete removal of colloids. Therefore, new calculations were performed allowing only for the precipitation of amorphous $\mathrm{ThO}_{2}$ (either "fresh" or "aged" from HATCHES version 20, with $\log \mathrm{K}_{\mathrm{sp}}=9.30$ and 8.50 respectively). As expected, the calculated values provide a better fit to the experimental measurements (Figure 4).

The HATCHES database provides stability constants for the complexation of Th with only two CDP ligands, isosaccharinate and acetate and the resulting model predicts no significant complexation of Th with either ligand under these experimental conditions. Mixed hydroxylISA complexes, such as $\mathrm{Th}(\mathrm{OH}) \mathrm{ISA}^{2+}, \mathrm{Th}(\mathrm{OH})_{3}(\mathrm{ISA})_{2}{ }^{-}$and $\mathrm{Th}(\mathrm{OH})_{4}(\mathrm{ISA})_{2}{ }^{2-}$, have been reported (Rai et al., 2009), albeit in the absence of calcium. Some authors have suggested the formation of a calcium-thorium-ISA (Ca:ISA:Th $=1: 2: 1$ ) complex in solution (Vercammen 
et al., 1999, 2001; Wieland et al., 2002; Tits et al., 2005; Gaona et al., 2008). Tits et al. (2005) reported a stability constant $\log \mathrm{K}=-5$ for the formation of the complex $\mathrm{CaTh}\left(\mathrm{H}_{2} \mathrm{ISA}\right)_{2}$ $\left(\mathrm{Ca}^{2+}+\mathrm{Th}^{4+}+2 \mathrm{H}_{4} \mathrm{ISA}^{-} \leftrightarrow \mathrm{CaTh}\left(\mathrm{H}_{2} \mathrm{ISA}\right)_{2}+4 \mathrm{H}^{+}\right) ;$as can be seen in Figure 5, the calculated solubility values with the stability constant reported by Tits et al. (2005) fit well with the experimental concentrations of Th in CDP.

\subsection{Through-diffusion experiments}

The apparent conflict when attempting to identify uranium precipitates collected from the centre of the NRVB blocks by EDXA $\left(\mathrm{CaUO}_{4}\right)$ and EXAFS (becquerelite) has been reported by other workers in similar in hyper-alkaline, calcium-rich systems. Smith et al. (2015) found that electron diffraction images as well as TEM-EDX data (transmission electron microscopy - EDX) correspond to calcium uranate for uranium solids formed in 'old cement leachates' (U concentration $\left.4.2 \times 10^{-6} \mathrm{M}\right)$. However, the results of X-ray Absorption Spectroscopy for solids generated at higher uranium concentrations $\left(2 \times 10^{-5} \mathrm{M}\right)$ fit better with a uranyl oxyhydroxide solid, such as becquerelite. These authors attributed the discrepancy between the two sets of data to changes in speciation caused by differences in the concentration of $U$ used in the experiments. In the present work, both EDXA and EXAFS analyses were carried out on the same sample; therefore, any disagreement between the two techniques cannot be attributed to differences in $\mathrm{U}$ concentration.

It is worth noting that, although the uranium solids originally introduced into the central well of the diffusion blocks were precipitated in $\mathrm{NaOH}$ solution, the solids at the end of the diffusion experiment correspond to $\mathrm{Ca}-\mathrm{U}$ compounds, proving that the transformation of $\mathrm{Na}$ $\mathrm{U}$ into $\mathrm{Ca}-\mathrm{U}$ solids is not only possible at high $\mathrm{pH}$, but also a rapid process.

BSEM images of the central well (Figure S2) show that, in the absence of CDP, the U(VI) precipitates do not penetrate into the cement matrix. This was further confirmed by EDXA 
mapping of the edge of the well (Figure 7a) and by micro-focus X-ray fluorescence mapping coupled with EXAFS. When CDP are present, BSEM, in combination with EDXA (Figure 7b) and microfocus X-ray fluorescence mapping, indicate discreet areas of higher uranium concentration clearly visible within the NRVB matrix. Uranium penetrated into the NRVB cylinder to a depth of approximately $40 \mu \mathrm{m}$ during the three years of the diffusion experiment in the presence of CDP; a slow but nevertheless measurable rate. EXAFS analysis of the uranium phase within the cement matrix corresponds to a U(VI) oxy-hydroxide precipitate, consistent with results for bulk precipitates removed from the central well.

The results obtained for the diffusion of U(VI) through intact NRVB contrast with the conclusions drawn previously by Felipe-Sotelo et al. (2012) from batch sorption to ground NRVB in the presence of CDP. In the latter work, the organic compounds caused an increase in the partition coefficient, which was attributed to adsorption of the cellulose degradation products to the surface of the cement. However, in the present work, the CDP caused the opposite effect. Discrepancies between the batch results and diffusion experiments using intact cement specimens could be due to the difference in the solid:liquid ratios, variation of the surface area available for retardation or even the exposure by grinding of fresh/reactive surfaces that would not have been accessible in the blocks. This highlights the need to reassess partition and diffusion coefficients obtained under batch condition as they may provide a non-conservative estimate of potential retardation.

The morphologies observed from the Th precipitates collected from the centre of the NRVB blocks (section 3.3) suggest rapid precipitation of hydrous phases. Altmaier et al. (2008) have also similar needle-like crystals on top of amorphous $\mathrm{ThO}_{2} \cdot \mathrm{xH}_{2} \mathrm{O}_{(\mathrm{am})}$ in solubility studies in Ca-rich systems (1.0-4.5 $\left.\mathrm{M} \mathrm{CaCl}_{2}\right)$ and $\mathrm{pH}$ values higher than 11.5 . 


\section{Conclusions}

Uranium solubility measurements undertaken on a series of hyper-alkaline solutions revealed systematic and significant differences between values obtained from the over- and undersaturation directions, which could reflect the slow dissolution kinetics of solids used in the under-saturation tests. Another hypothesis is that differences in the inventories of $\mathrm{Ca}$ and $\mathrm{Na}$ available for precipitation in the two experiments may have caused changes in the stoichiometry of the solubility limiting phases.

Uranium solubility in a bespoke backfill, $\mathrm{NRVB}$, is similar to that in $95 \%$-saturated $\mathrm{Ca}(\mathrm{OH})_{2}$ solution. The CDP increased the solubility of $U$ by an order of magnitude in comparison to NRVB alone. The presence of CDP appeared to affect only aqueous speciation; there is no evidence of any change in the solubility-controlling phases produced. Previous studies (Atkins et al., 1992) identified several mineral phases that could be responsible for the immobilisation of U(VI) in cement systems; these include two mineral phases present in nature, becquerelite $\quad\left(\mathrm{Ca}\left(\mathrm{UO}_{2}\right)_{6} \mathrm{O}_{4}(\mathrm{OH})_{6} \cdot 8 \mathrm{H}_{2} \mathrm{O}\right)$ and uranophane $\left(\mathrm{Ca}\left(\mathrm{UO}_{2}\right)_{2} \cdot 2 \mathrm{H}_{2} \mathrm{O} \cdot \mathrm{SiO}_{2} \cdot 6 \mathrm{H}_{2} \mathrm{O}\right)$ as well as synthetic phases such as $\mathrm{Ca}_{2} \mathrm{UO}_{5} \cdot 1.3-1.7 \mathrm{H}_{2} \mathrm{O}$. There was little evidence of uranophane or other silicate formation in the present study. Compositionally, the solids most closely resemble calcium uranate $\left(\mathrm{CaUO}_{4}\right)$ whereas EXAFS spectra suggest a uranyl oxy-hydroxide, possibly becquerelite.

Metallic iron, employed as a surrogate for corroding steel, also caused no change in mineralogy or uranium oxidation state. Characterisation of the solids generated when a more potent reducing agent, $\mathrm{Na}_{2} \mathrm{~S}_{2} \mathrm{O}_{4}$, was used revealed only partial reduction of $\mathrm{U}(\mathrm{VI})$ to $\mathrm{U}(\mathrm{IV})$. EXAFS analysis of the solids indicated $U$ atoms in a chemical environment intermediate between uraninite and becquerelite.

Thermodynamic modelling using amorphous $\mathrm{ThO}_{2}$ as the solubility-controlling phase generally provided a satisfactory fit to the experimental data. CDP cause a significant 
increase in thorium solubility and thermodynamic models considering the formation of the complex $\mathrm{Th}\left(\mathrm{H}_{2} \mathrm{ISA}\right)_{2} \mathrm{Ca}$ provided a good fit with the experimental results.

No breakthrough was observed for either $\mathrm{U}$ or Th in diffusion experiments through intact cylinders of NRVB. Subsequent BSEM imaging and microfocus X-ray fluorescence on cut sections confirmed that $\mathrm{U}$ had in fact penetrated $40 \mu \mathrm{m}$ into the cement matrix over the threeyear duration of the experiments, but only in a solution containing CDP. Thorium rapidly precipitates forming a gel-like coating in the central well of the NRVB cylinders and did not penetrate into the matrix whether or not CDP were present.

Some discrepancies were found when attempting to identify largely amorphous uranium phases using complementary techniques. Whereas SEM-EDX analyses on precipitated solids indicate formation of calcium uranate, EXAFS data for the same material suggest a closer fit to becquerelite. This inconsistency may reflect the fact that the solubility-controlling phase is not pure or presents an intermediate chemical composition that has not yet been fully characterised. It also highlights the complexity of cementitious systems and the need for standard matrices allowing reliable identification of solid phases by advanced spectroscopic methods. Another aspect that will require further investigation, irrespective of the cementitious material used for the immobilisation and/or backfilling of the radioactive waste, is the difference in the experimental results between batch sorption studies and diffusion through intact cement blocks.

\section{Acknowledgements}

We are grateful to Radioactive Waste Management (RWM) for funding this work. The authors would like to thank the Diamond Light Source for access to beamlines I18 and B18, in particular, Prof Fred Mosselmans, Prof Andy Dent, Dr Steve Parry (Diamond Light Source Ltd) and Dr Sam Shaw (Manchester University, Env-Rad-Net) for their assistance. A.E.M. 
and L.P.F. publish with the permission of the Executive Director of the British Geological Survey (NERC).

\section{References}

Altmaier, M., Neck, V., Fanghänel, T., 2008.Solubility of Zr(IV), Th(IV) and Pu(IV) hydrous oxides in $\mathrm{CaCl} 2$ solutions and the formations of ternary $\mathrm{Ca}-\mathrm{M}(\mathrm{IV})-\mathrm{OH}$ complexes. Radiochim. Acta. 96, 541-550.

Atkins, M., Glasser, F.P., 1992. Application of Portland cement-based materials to radioactive waste immobilization. Waste Manage. 12, 105-131.

Bamforth, P.B., Baston, G.M.N, Berry, J.A., Glasser, F.P., Heath, T.G., Jackson, C.P., Savage, D., Swanton, S.W., 2012. Cement materials for use as backfill, sealing and structural materials in geological disposal concepts. A review of current status. Serco report (SERCO/005125/001 Issue 3) for NDA RWMD RP0618-252A.

Baston, G.M.N., Brownsword, M., Cross, J.E., Hobley, J., Moreton, A.D., Smith-Briggs, J.L., Thomason, H.P., 1993. The solubility of uranium in cementitious near-field chemical conditions. AEA Technology Report, NSS/R222.

Baston, G.M.N., Heath, T.G., Hunter, F.M.I., 2008. Summary of additions and amendments to data in the HATCHES chemical thermodynamic database 2002 to 2007. Serco Report, SA/ENV-0934 to Nirex NR3169/010.

Baston, G.M.N., Cowper, M.M., Heath, T.J., Marshall, T.A, Swanton, S.W., 2012. The effect of cellulose degradation products on thorium sorption on hematite: studies of a model ternary system. Mineral. Mag. 76, 3381-3390.

Biddle, P., Greenfield, B.N., Pilkington, N.J., Spindler, M.W., 2000. Further studies on the effects of the products from the anaerobic degradation of cellulosic wastes in the near field. AEA Technology Report AEAT/ERRA-0154. 
Brendebach, B., Altmaier, M., Rothe, J., Neck, V., Denecke, M., 2007. EXAFS study of aqueous $\mathrm{Zr}^{\mathrm{IV}}$ and $\mathrm{Th}^{\mathrm{IV}}$ complexes in alkaline $\mathrm{CaCl}_{2}$ solutions: $\mathrm{Ca}_{3}\left[\mathrm{Zr}(\mathrm{OH})_{6}\right]^{4+}$ and $\mathrm{Ca}_{4}\left[\mathrm{Th}(\mathrm{OH})_{8}\right]^{4+}$. Inorg. Chem. 46, 6804-6810.

Bube, C., Mezt, V., Schild, D., Rothe, J., Dardenne, K., Lagos, M., Plaschke, M., Kienzler, B., 2014. Combining thermodynamic simulations, element and surface analytics to study U(VI) retention in corroded cement monoliths upon >20 years of leaching. Phys. Chem. Earth. 70-71, 53-59.

Burciaga-Valencia, D.C., Reyes-Cortés, M., Reyes-Rojas, A., Rentería-Villalobos, M., Esparza-Ponce, H., Fuentes-Cobas, L., Fuentes-Montero, L., Silva-Sáenz, M., HerreraPeraza, E., Muñoz, A., Montero-Cabrera, M.E., 2010. Characterization of uranium minerals from Chihuahua using synchrotron radiation. Rev. Mex. Fis., S 56, 75-81.

Casas, I., Bruno, J., Cera, E., Finch, R.J., Ewing, R.C., 1997. Characterisation and dissolution behaviour of a becquerelite from Shinkolobwe, Zaire. Geochim. Cosmochim Ac. 61, 38793884.

Clacher, A.P., Cowper, M.M., 2011. Effect of ADVA Cast 551 on the solubility of plutonium(IV) and uranium(VI). Serco Report SERCO/TAS/003145/001 for NDA RWMD NPO003662.Colàs, E., Grivé, M., Rojo, I., Duro, L., 2011. Solubility of $\mathrm{ThO}_{2} \cdot \mathrm{H}_{2} \mathrm{O}_{(\mathrm{am})}$ in the presence of gluconate. Radiochim. Acta. 99, 269-273.

Colàs, E., Grivé, M., Rojo, I., 2013a. Complexation of uranium(VI) by gluconate in alkaline solutions. J. Solution Chem. 42, 1545-1557.

Colàs, E., Grivé, M., Rojo, I., Duro, L., 2013b. The effect of gluconate and EDTA on thorium solubility under simulated cement porewater conditions. J. Solution Chem. 42, 1680-1690.

Cowper, M.M., Baker, S., Chambers, A.V., Heath, T.G., Mihara, M., Williams, S.J., 2006. The sorption of thorium and americium onto fresh and degraded ordinary Portland cement and onto green tuff. Mater. Res. Soc. Symp. Proc. 932, 925-932. 
Dent, A.J., Cibin, G., Ramos, S., Smith, A.D., Scott, S.M., Varandas, L., Pearson, M.R., Krumpa, N.A., Jones, C.P., Robbins, P.E., 2009. A core XAS spectroscopy beamline for Diamond. J. Phys. Conf. Ser. 190, 012039.

Ewart, F.T., Smith-Briggs, J.L., Thomason, H.P., Williams, S.J., 1992. The solubility of actinides in a cementitious near-field environment. Waste Manage. 12, 241-252.

Fanghänel, Th., Neck, V., 2002. Aquatic chemistry and solubility phenomena of actinide oxide/hydroxides. Pure Appl. Chem. 74, 1895-1907.

Felipe-Sotelo, M., Hinchliff, J., Evans, N., Warwick, P., Read, D., 2012. Sorption of radionuclides to a cementitious backfill material under near-field conditions. Min. Mag. 76, 3401-3410.

Felipe-Sotelo, M., Hinchliff, J., Evans, N.D.M., Williams, S., Read, D., 2014. Radial diffusion of radiocaesium and radioiodide through cementitious backfill. Phys. Chem. Earth. 70-71, 60-70.

Felipe-Sotelo, M., Hinchliff, J., Field, L.P., Milodowski, A.E., Holt, J.D., Taylor, S.E., Read, D., 2016a. The solubility of nickel and its migration through the cementitious backfill of a geological disposal facility for nuclear waste. J. Hazard. Mater. 314, 1-9.

Felipe-Sotelo, M., Hinchliff, J., Evans, N.D.M, Read, D., 2016b. Solubility constraints affecting the migration of selenium through the cementitious backfill of a geological disposal facility. J. Hazard. Mater. 305, 21-29.

Francis, A.J., Cather, R., Crossland, I.G., 1997. Development of the Nirex Reference Vault Backfill; report on current status in 1994. Nirex Science Report S/97/014, United Kingdom Nirex Limited.

Fujiwara, K., Yamana, H., Fujii, T., Kawamoto, K., Sasaki, T., Moriyama, H., 2005. Solubility of uranium(IV) hydrous oxide in high $\mathrm{pH}$ solution under reducing conditions. Radiochim. Acta. 93, 347-350. 
Gaona, X., Montoya, V., Colàs, E., Grivè, M., Duro, L., 2008. Review of the complexation of tetravalent actinides by ISA and gluconate under alkaline to hyper-alkaline conditions. J. Contam. Hydrol. 102, 217-227.

Gayer, K.H., Leider, H., 1955. The solubility of uranium trioxide, $\mathrm{UO}_{3} \cdot \mathrm{H}_{2} \mathrm{O}$, in solutions of sodium hydroxide and perchloric acid at $25^{\circ}$. J. Am. Chem. Soc. 77, 1448-1450.

Greenfield, B.F., Hurdus, M.H., Spindler, M.W., Thomason, H.P., 1997. The effects of the products from the anaerobic degradation of cellulose on the solubility and sorption of radionuclides in the near field. AEA Technology Report, NSS/R376.

Grivé, M., Duro, L., Domènech, C., Salas, J. Redox evolution of a cementitious geological disposal facility. In Proceedings of the $13^{\text {th }}$ International High-Level Radioactive Waste Management Conference (IHLRWMC): American Nuclear Society, 692-700.

Harfouche, M., Wieland, E., Dähn, R., Fujita, T., Tits, J., Kunz, D., Tsukamoto, M., 2006. EXAFS study of U(VI) uptake by calcium silicate hydrates. J.Colloid Interf. Sci. 303, 195204.

Humphreys, P.N., Laws, A., Dawson, J., 2010. A review of cellulose degradation and the fate of degradation products under repository conditions. Serco Report to NDA, WT 150515.

Jantzen, C., Johnson, A., Read, D., Stegemann, J.A., 2010. Cements in waste management. Adv. Cem. Res. 22, 225-231.

King, W.D., Wilmarth, W.R., Hobbs, D.T., Edwards, T.B., 2008. Recent studies of uranium, and plutonium chemistry in alkaline radioactive waste solutions. J. Alloy. Compd. 458, 158160.

Kitamura, A., Fujiwara, K., Mihara, M., Cowper, M., Kamei, G., 2013. Thorium and americium solubilities in cement pore water containing superplasticiser compared with thermodynamic calculations. J. Radioanal. Nucl. Ch. 298, 485-493. 
Markovaara-Koivisto, M., Read, D., Lindberg, A., Siitari-Kauppi, M., Togneri, L., 2009. Geology of the Sievi, Kuru and Askola sites: Uranium mineralogy at Askola. Research Report TKK-GT-A-4.

Moroni, L.P., Glasser, F.P, 1995. Reactions between cement components and U(VI) oxide. Waste Manage. 15, 243-254.

Neck, V., Müller, R., Bouby, M., Altmaier, M., Rothe, J., Denecke, M.A., Kim, J.I., 2002. Solubility of amorphous Th(IV) hydroxide - application of LIBD to determine the solubility product and EXAFS for aqueous speciation. Radiochim. Acta. 90, 485-494.

Neck, V., Altmaier, M., Müller, R., Bauer, A., Fanghänel, Th., Kim, J.I., 2003. Solubility of crystalline thorium dioxide, Radiochim. Acta. 91, 253-262.

Newville, M., Ravel, B., Haskel, D., Rehr, J.J., Stern, E.A., Yacoby, Y., 1995. Analysis of multiple-scattering XAFS data using theoretical standards. Physica B. 208-209, 154-156.

Nuclear Decommissioning Authority, 2010. Geological disposal. Near field evolution status report. NDA report NDA/RWMD/033.

Pagoaga, M.K., Appleman, D.E., Stewars, J.M., 1987. Crystal structures and crystal chemistry of the uranyl oxide hydrates becquerelite, billietite, and protasite. Am. Mineral. 72, $1230-1238$.

Priyadarshini, N., Sampath, M., Kumar, S., Mudali, U.K., 2016. Light scatering investigation of the hydrolized thorium(IV) colloids and polymers. J. Radioanal. Nucl. Chem. 307, 25-30. Rai, B.D., Felmy, A.R., Hess, N.J., LeGore, V.L., McCready, D.E., 2002. Thermodynamics of the U(VI)-Ca ${ }^{2+}-\mathrm{Cl}^{-}-\mathrm{OH}-\mathrm{H}_{2} \mathrm{O}$ system. Solubility product of becquerelite. Radiochim. Acta. 90, 495-503.

Rai, D., Yui, M., Moore, D.A., Rao, L., 2009. Thermodynamic model for $\mathrm{ThO}_{2(\mathrm{am})}$ solubility in isosaccharinate solutions. J. Solution Chem. 38, 1573-1597. 
Rothe, J., Brendebach, B., Bube, C., Dardenne, K., Denecke, M.A., Kienzler, B., Mezt, V., Prüßmann, T., Rickers-Appel, K., Schild, D., Soballa, E., Vitova, T., 2013. Characterisation of U(VI)-phase in corroded cement product by micro( $\mu$ )-spectroscopic methods. J. Phys. Conf. Ser. 430, 012114.

Salah, S., Wang, L., 2014. Speciation and solubility calculations for waste relevant radionuclides in Boom Clay. SCK-CEN External Report 14/Ssa/P-16.

Sandino, M.C.A., Grambow, B., 1994. Solubility equilibria in the U(VI)-Ca-K-Cl- $\mathrm{H}_{2} \mathrm{O}$ system - Transformation of schoepite into becquerelite and compreignacite. Radiochim. Acta. 66-67, 37-47.

Smith, K.F., Bryan, N.D., Swinburne, A.N., Bots, P., Shaw, S., Natrajan, L.S., Mosselmans, J.F.W., Livens, F.R., Morris, K., 2015. U(VI) behaviour in hyper-alkaline calcite systems. Geochim. Cosmochim. Ac. 148, 343-359.

Sutton, M., Warwick, P., Hall, A., Jones, C., 1999. Carbonate induced dissolution of uranium containing precipitates under cement leachate conditions. J. Environ. Monitor. 1, 177-182.

Tits, J., Wieland, E., Bradbury, M.H., Dobler, J.P., 2000. The uptake of Eu(III) and Th(IV) by cement-type minerals in the alkaline disturbed zone of a nuclear waste repository. Proc. 6th Int. Cong. Appl. Mineralogy. 2, 691-694.

Tits, J., Wieland, E., Bradbury, M.H., 2005. The effect of isosaccharinic acid and gluconic acid on the retention of $\mathrm{Eu}(\mathrm{III}), \mathrm{Am}(\mathrm{III})$ and Th(IV) by calcite. Appl. Geochem. 20, 20822096.

Thomason, H.P., Williams, S.P., 1992. Near-field solubility studies. AEA Decommissioning \& Radwaste NSS/R128.

Valsami-Jones, E., Ragnarsdóttir, V., 1997. Solubility of uranium oxide and calcium uranate in waters and $\mathrm{Ca}(\mathrm{OH})_{2}$-bearing solutions. Radiochim. Acta. 79, 249-257. 
van der Lee, J., 1998. Thermodynamic and mathematical concepts of JCHESS. Technical Report LHM/RD/98/39, CIG.

van Es, E., Hinchliff, J., Felipe-Sotelo, M., Milodowski, A.E., Field, L.P., Evans, N.D.M., Read, D., 2015. Retention or chloride-36 by a cementitious backfill. Mineral. Mag. 79, 12971305.

Vercammen, K., Glaus, M.A., van Loon, L.R., 1999. Evidence of the existence of complexes between Th(IV) and $\alpha$-isosaccharinic acid under alkaline conditions. Radiochim. Acta. 84, 221-224.

Vercammen, K., Glaus, M.A., van Loon, L.R., 2001. Complexation of Th(IV) and Eu(III) by $\alpha$-isosaccharinic acid under alkaline conditions Radiochim. Acta. 89, 393-401.

Vochten, R., van Haverbeke, L., 1990. Transformation of schoepite into uranyl oxide hydrates - becquerelite, billietite and wolsendorfite. Miner. Petrol. 43, 44-45.

Walther, C., Fuss, M., Büchner, S., 2008. Formation and hydrolysis of polynuclear Th(VIV) complexes - a nano-electrospray mass spectrometry study. Radiochim. Acta. 96, 411-425.

Wieland, E., Tits, J., Dobler, J.P., Spieler, P., 2002. The effect of $\alpha$-isosaccharinic acid on the stability of and Th(IV) uptake by hardened cement paste. Radiochim. Acta. 90, 683-688.

Wieland, E., Macé, N., Dähn, R., Kunz, D., Tits, J., 2010. Macro- and micro-scale studies on U(VI) immobilization in hardened cement pastes. J. Radioanal. Nucl. Ch. 286, 793-800.

Wierczinski, B., Helfer, S., Ochs, M., Skanemark, G., 1998. Solubility measurements and sorption studies of thorium in cement pore water. J. Alloy Compd. 271-273, 272-276.

Wilk, C.M. 2004. Solidification/stabilization treatment and examples of use at port facilities. ASCE Conf. P. 10-19.

Yamamura, T., Kitamura, A., Fukui, A., Nishikawa, S., Yamamoto, T., Moriyama, H., 1998. Solubility of U(VI) in highly basic solutions. Radiochim. Acta. 83, 139-146. 


\section{Figure captions}

Figure 1.- Final concentrations after 1340 days equilibration for (a) $U$ and (b) Th.

Figure 2- Total uranium and calculated concentration (dotted lines) in: (a) $0.02 \mathrm{M} \mathrm{NaOH}$; (b) $95 \%$ saturated $\mathrm{Ca}(\mathrm{OH})_{2}$ and (c) NRVB equilibrated water.

Figure 3- Total uranium and calculated concentration (dotted lines) in: (a) CDP produced in NRVB; (b) $\mathrm{CDP}$ in the presence of $\mathrm{Fe}$ coupons and (c) $\mathrm{CDP}$ in the presence of $0.03 \mathrm{M} \mathrm{Na} \mathrm{S}_{2} \mathrm{O}_{4}$.

Figure 4- Total thorium and calculated concentration (dotted lines) in: (a) $0.02 \mathrm{M} \mathrm{NaOH}$; (b) $95 \%$ saturated $\mathrm{Ca}(\mathrm{OH})_{2}$ and (c) NRVB equilibrated water.

Figure 5- Total thorium and calculated concentration (dotted lines) in CDP produced in NRVB.

Figure 6- (a) $\mathrm{k}^{3}$-weighted and (b) $\chi$ functions with Fourier transforms for $\mathrm{U}$ precipitates in the presence of CDP with the reducing agents $0.03 \mathrm{M} \mathrm{Na}_{2} \mathrm{~S}_{2} \mathrm{O}_{4}$ and Fe.

Figure 7- Backscattering images and EDXA elemental mapping of the edge of the central well of the NRVB blocks used in the diffusion of U(VI): (a) without CDP and (b) with CDP. 
(a)

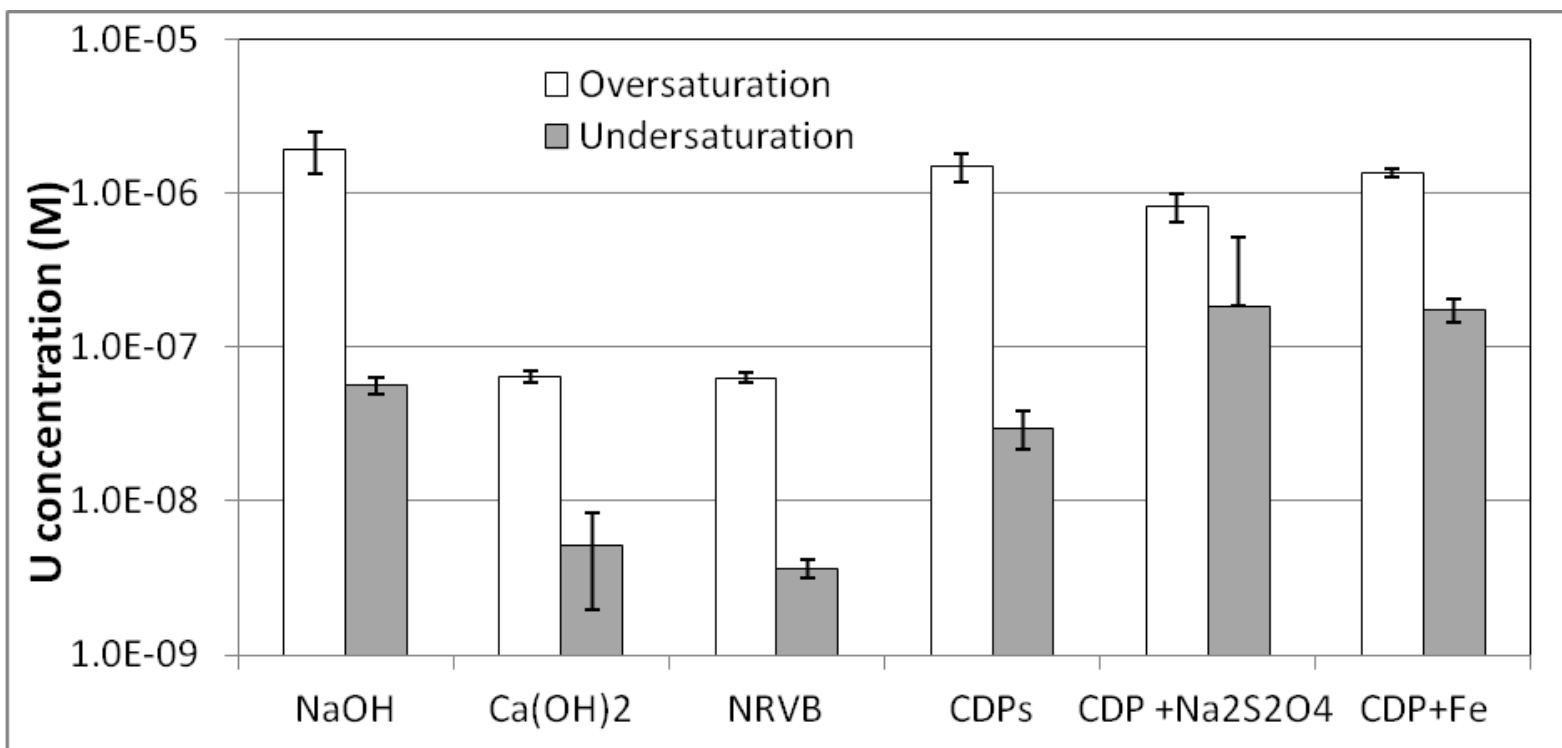

(b)

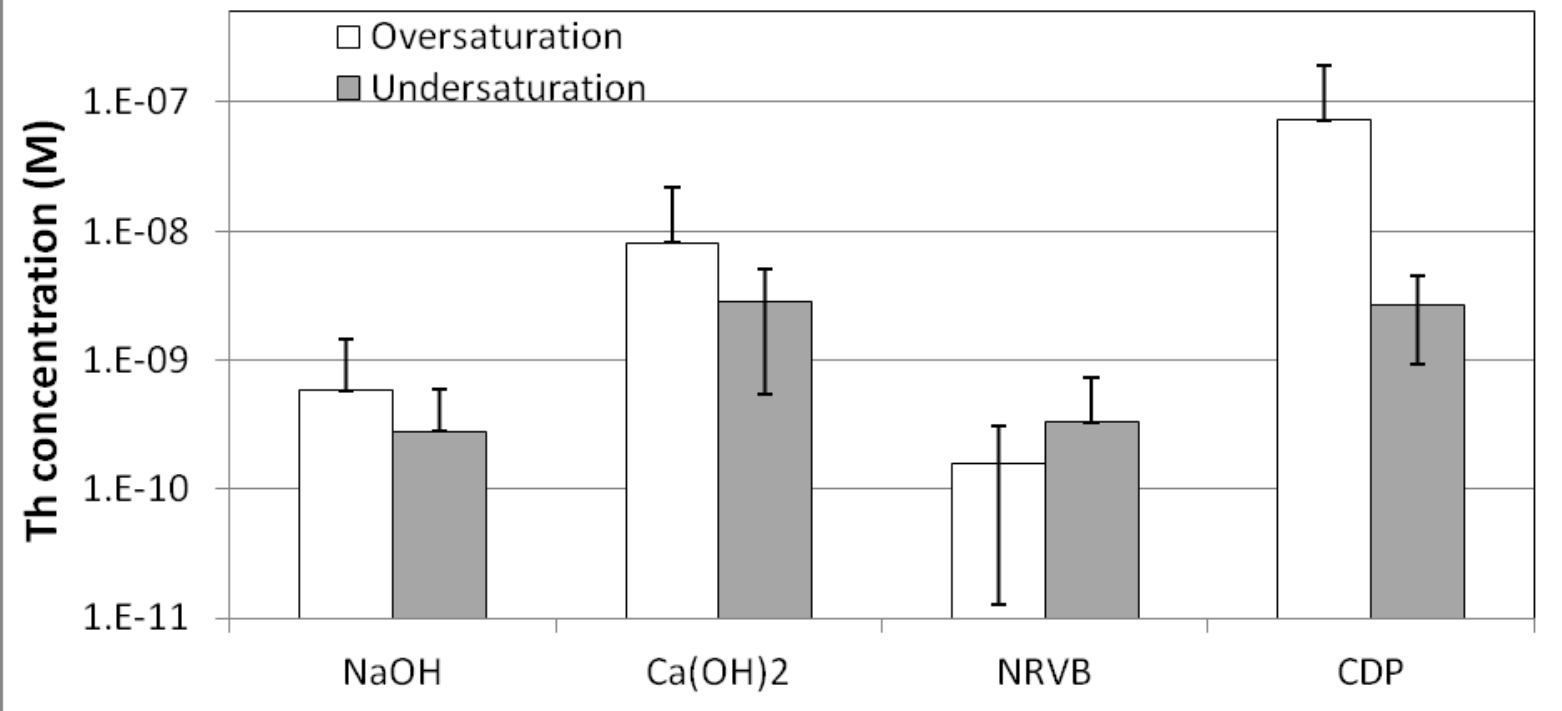

Figure 1 
(a)

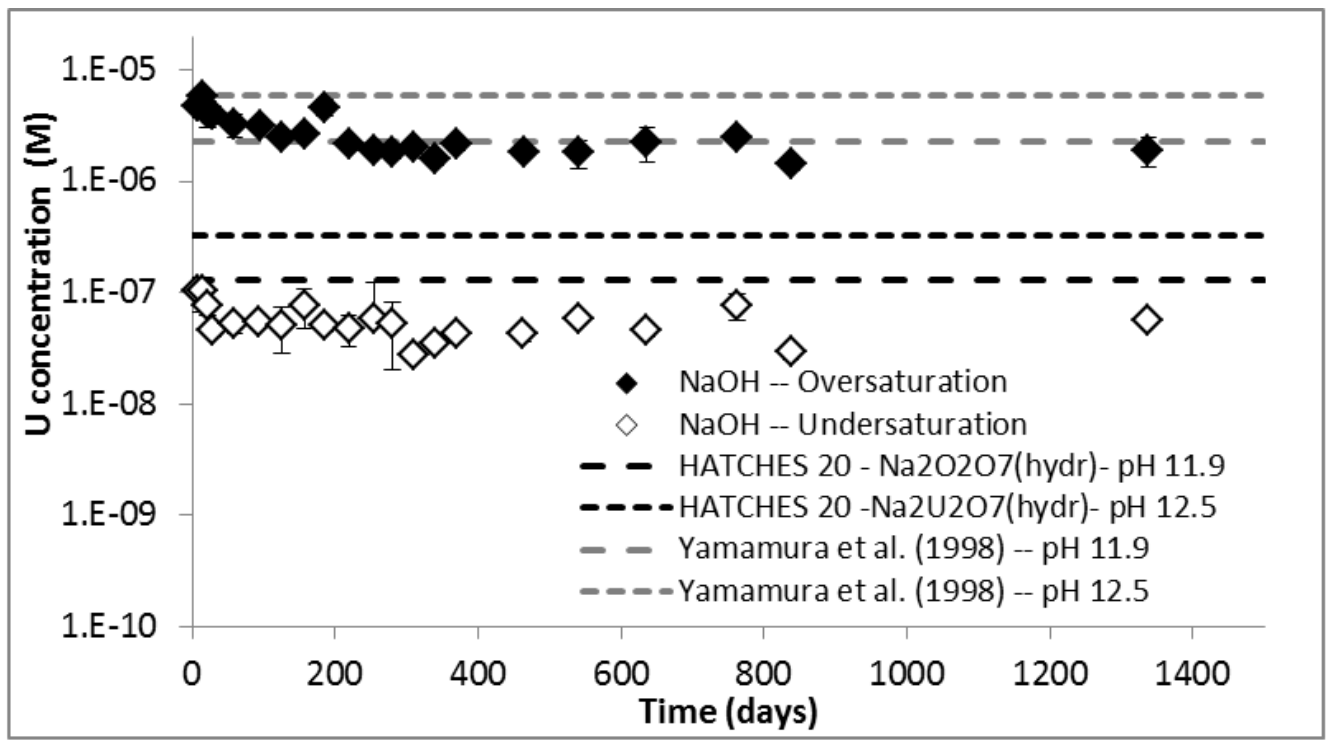

(b)

(c)
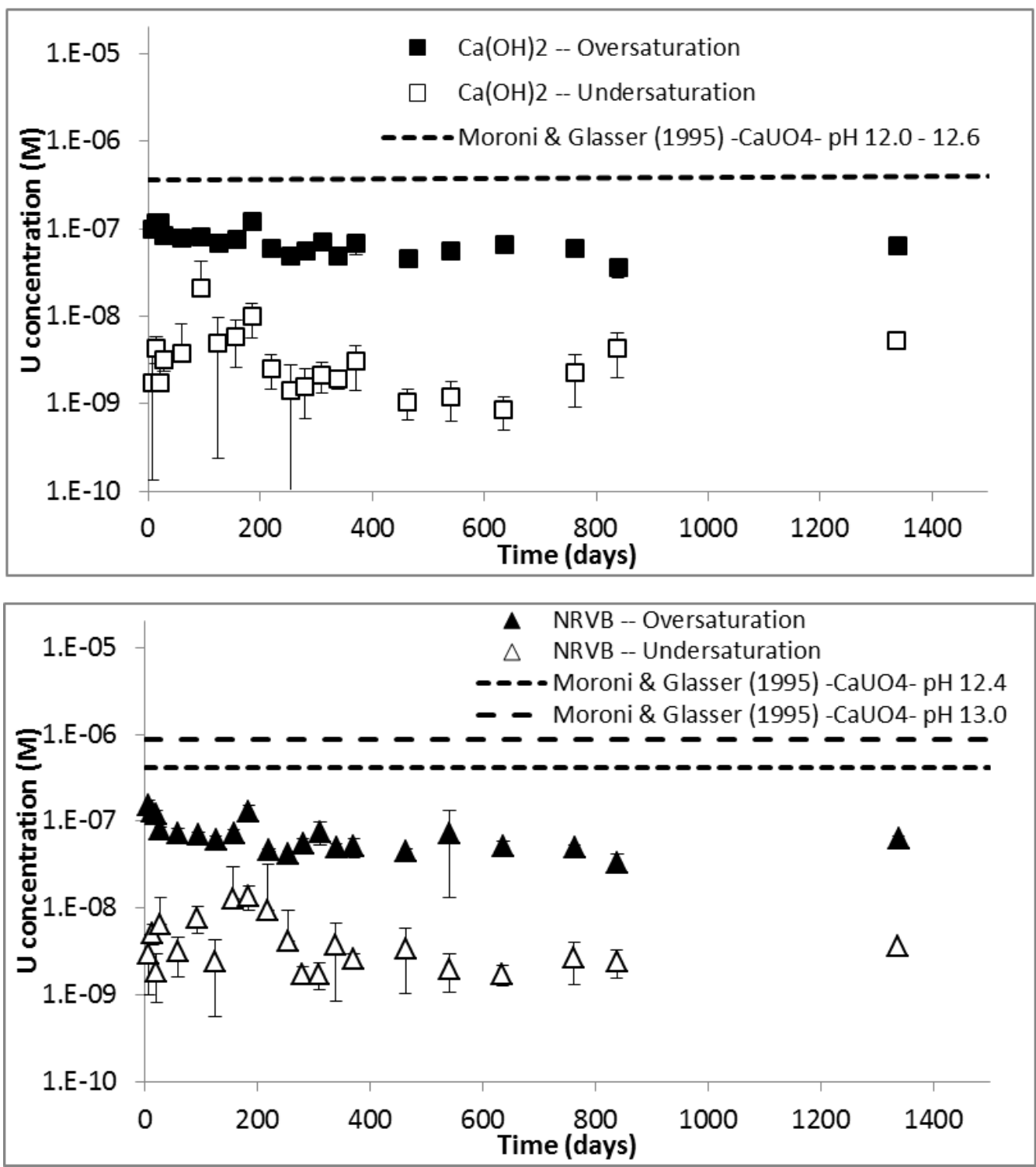

Figure 2 
(a)

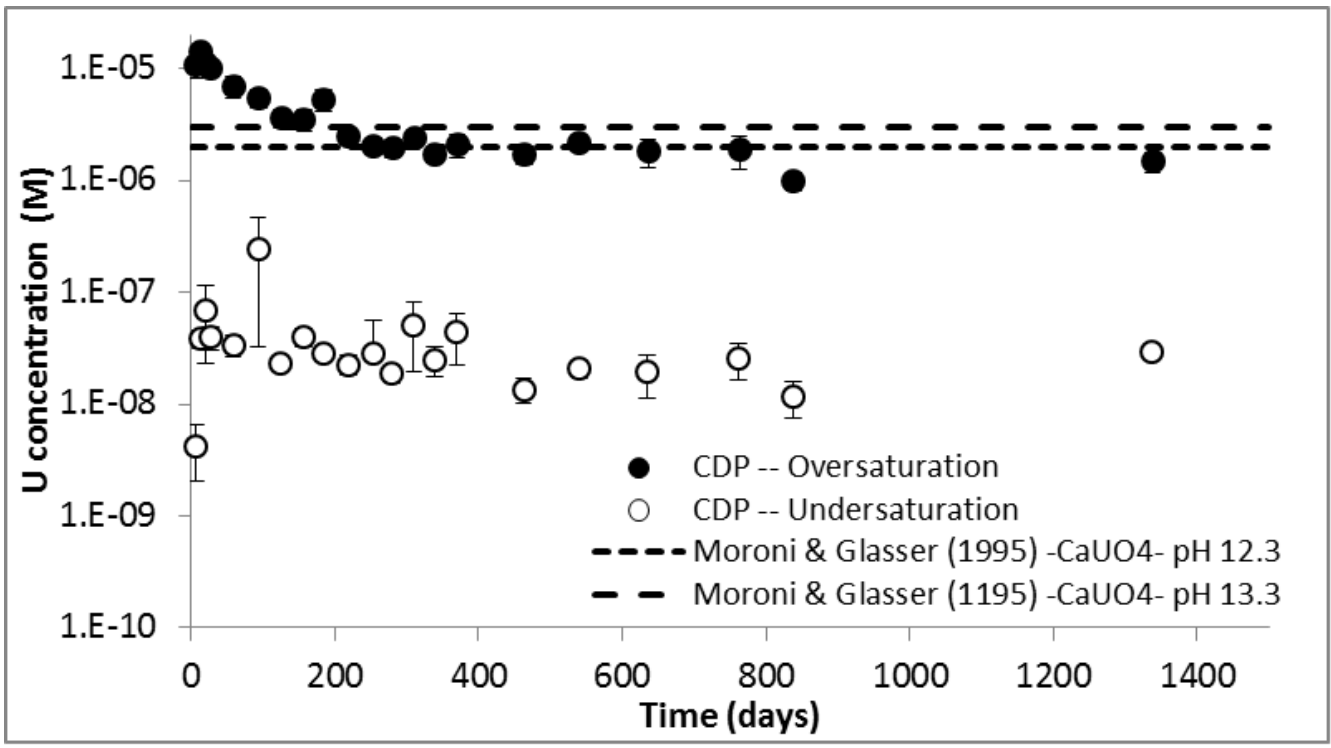

(b)

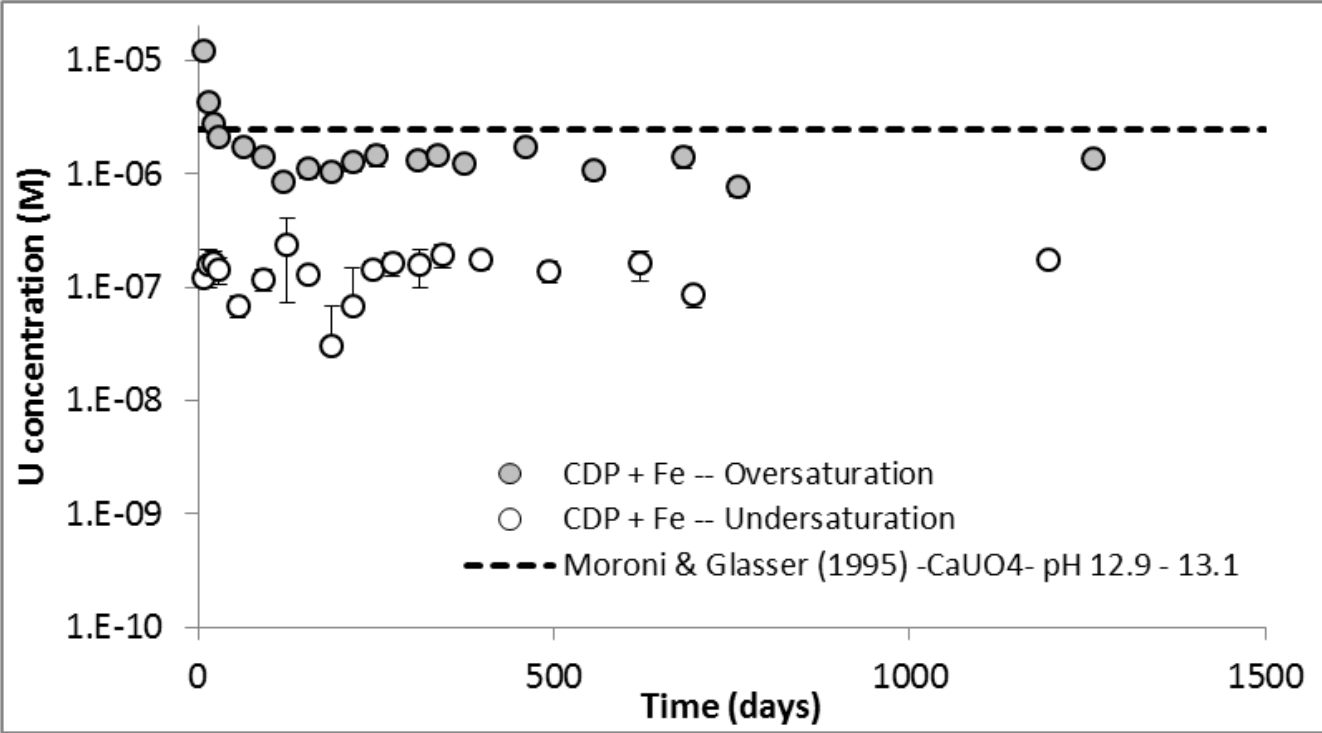

(c)

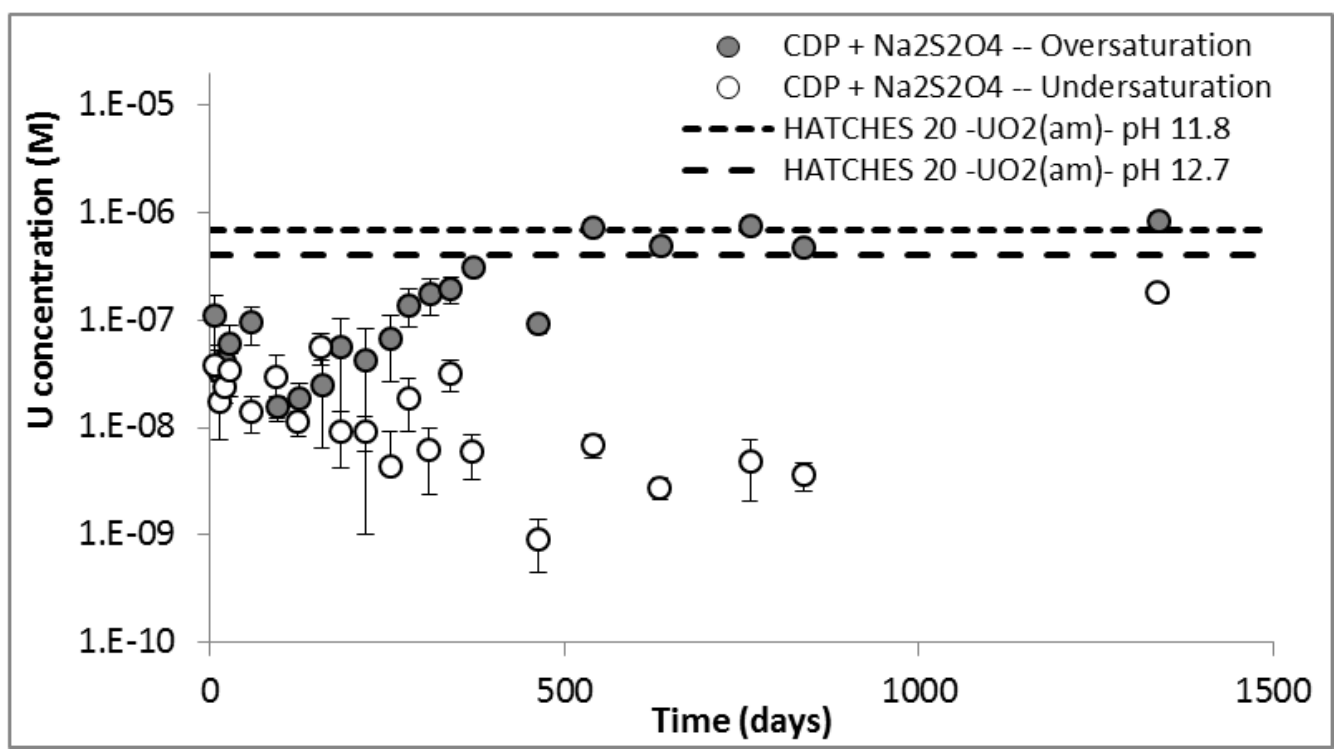


(a)

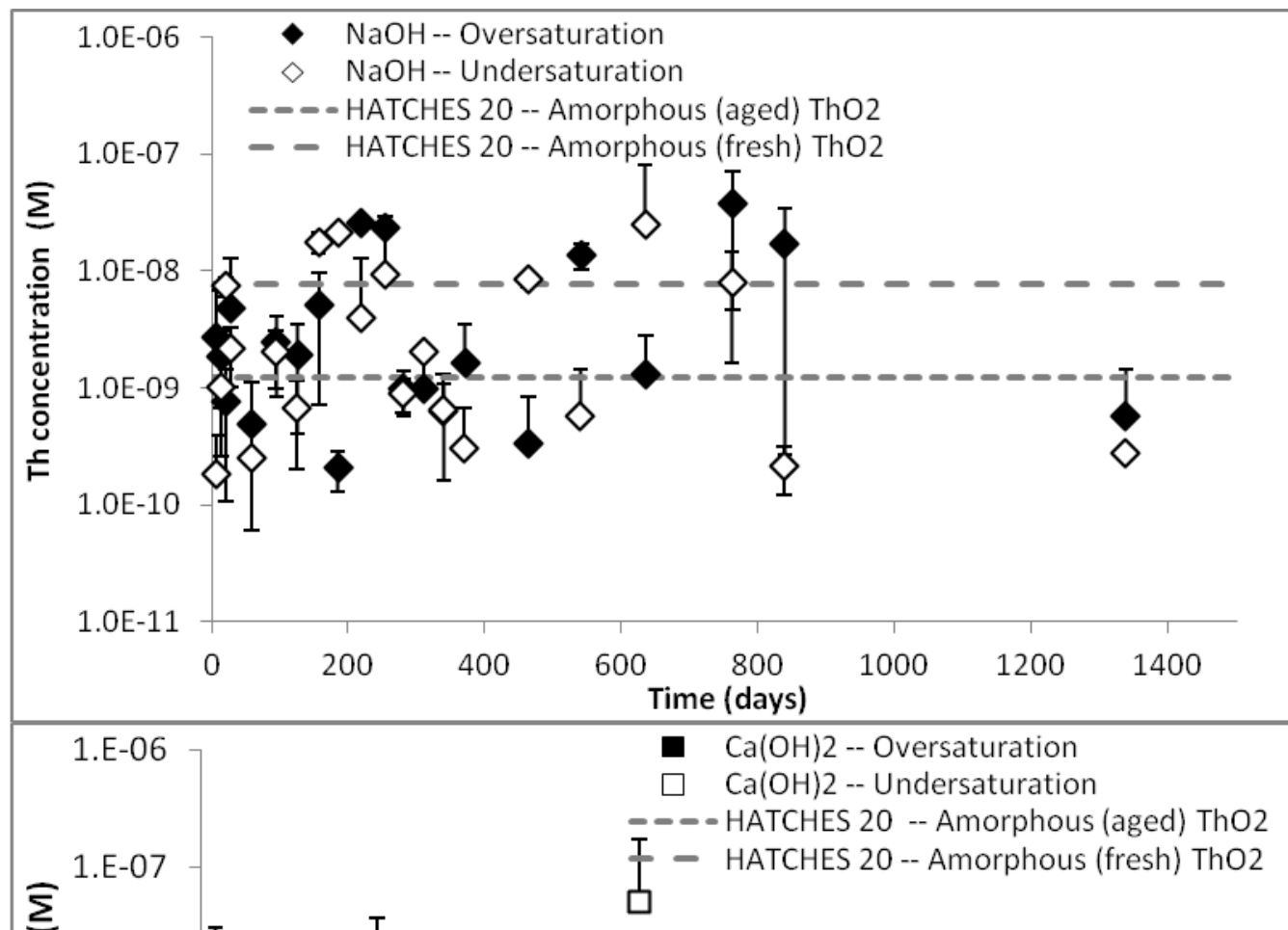

(b)

(c)

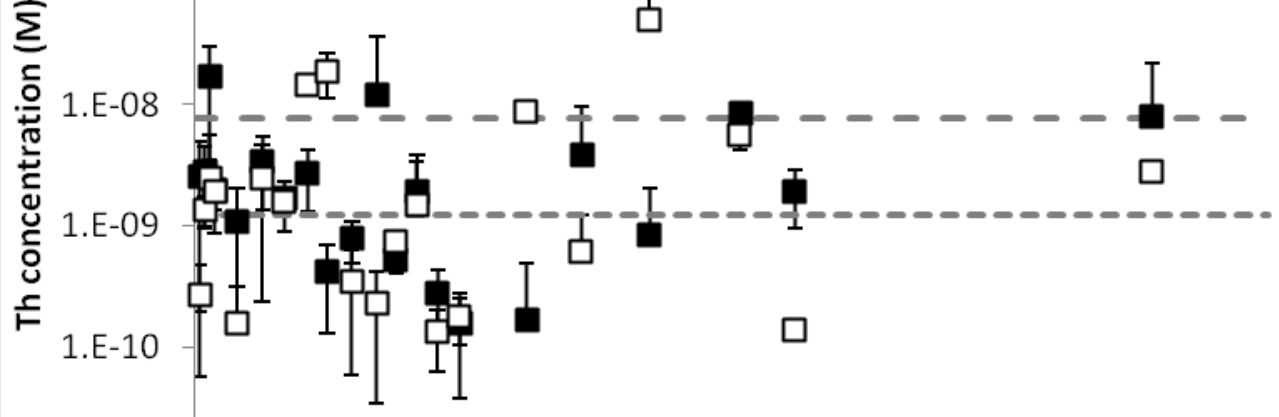

1.E-11

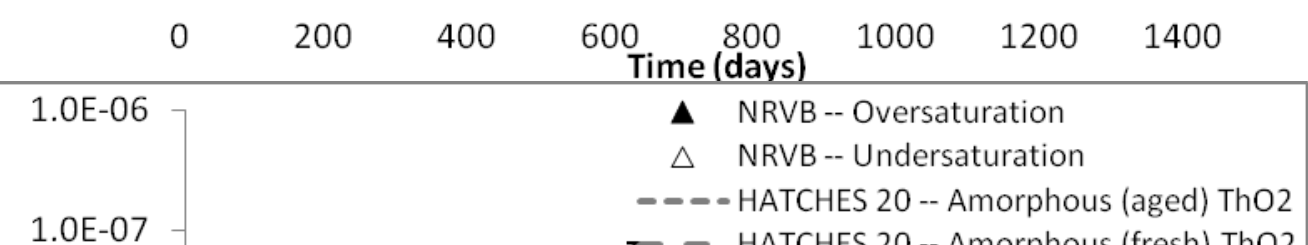

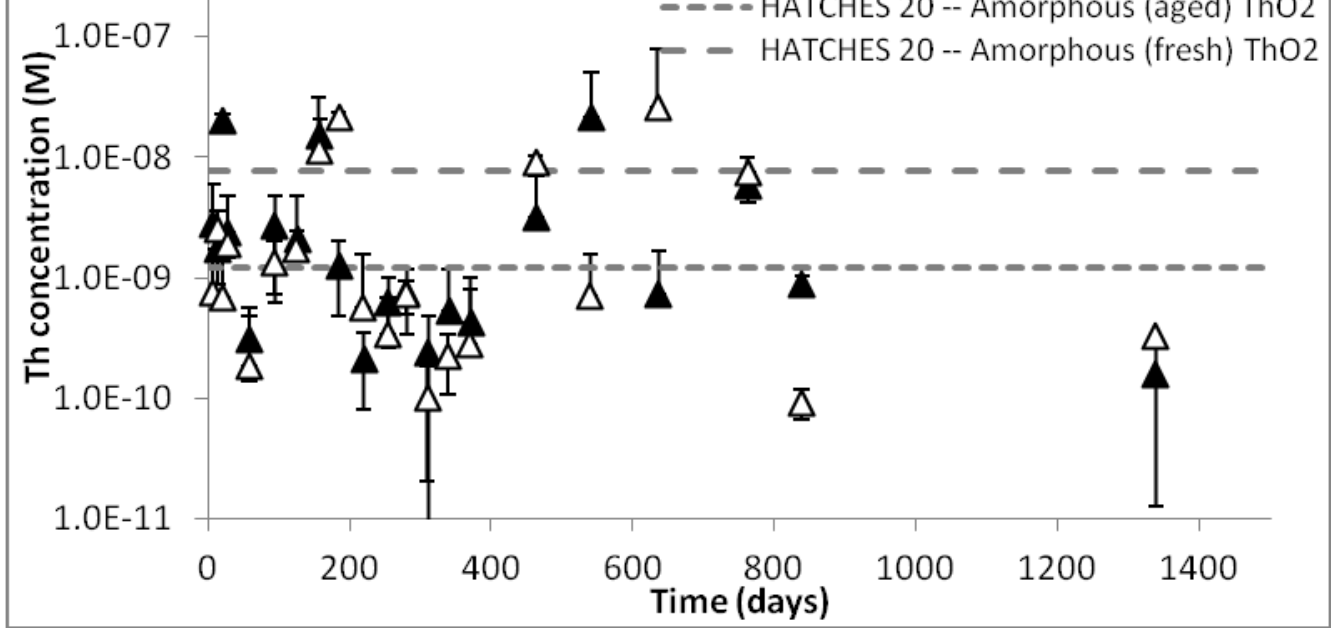

Figure 4 


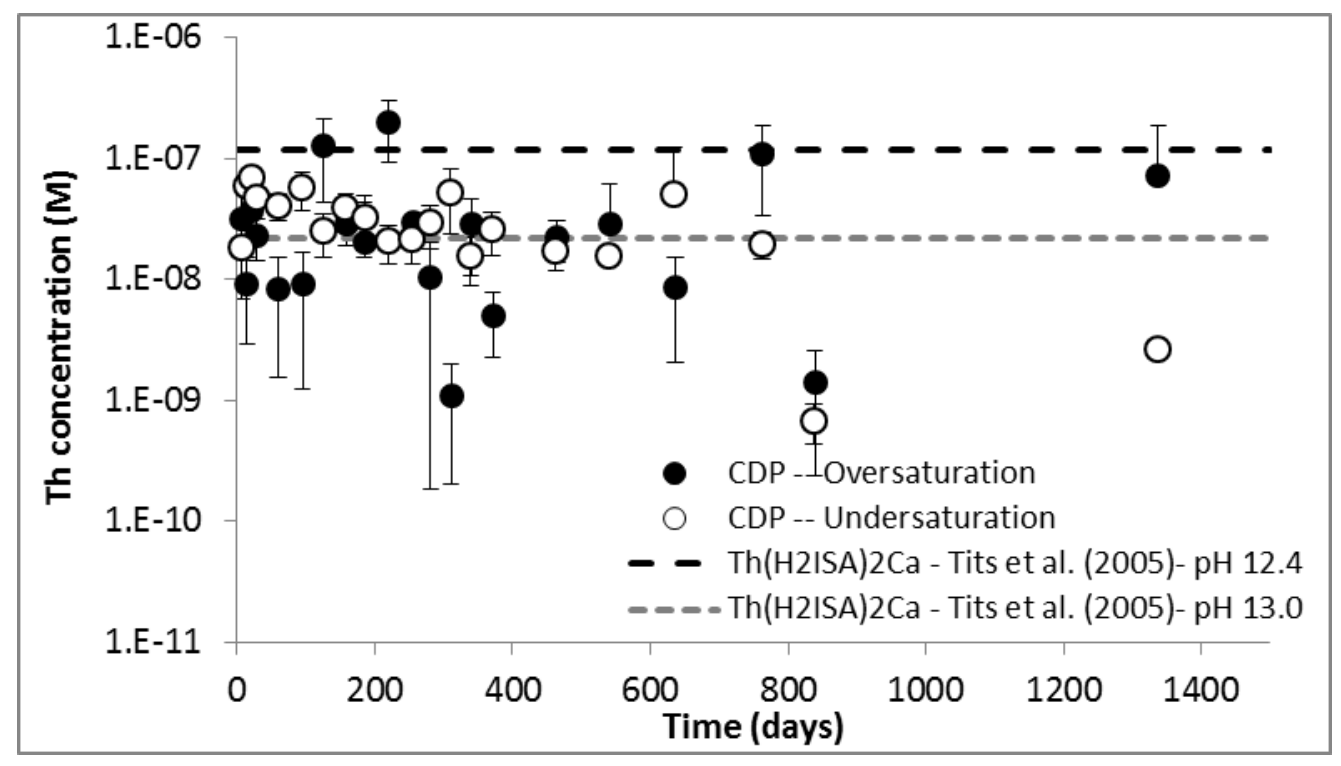

Figure 5 
(a)

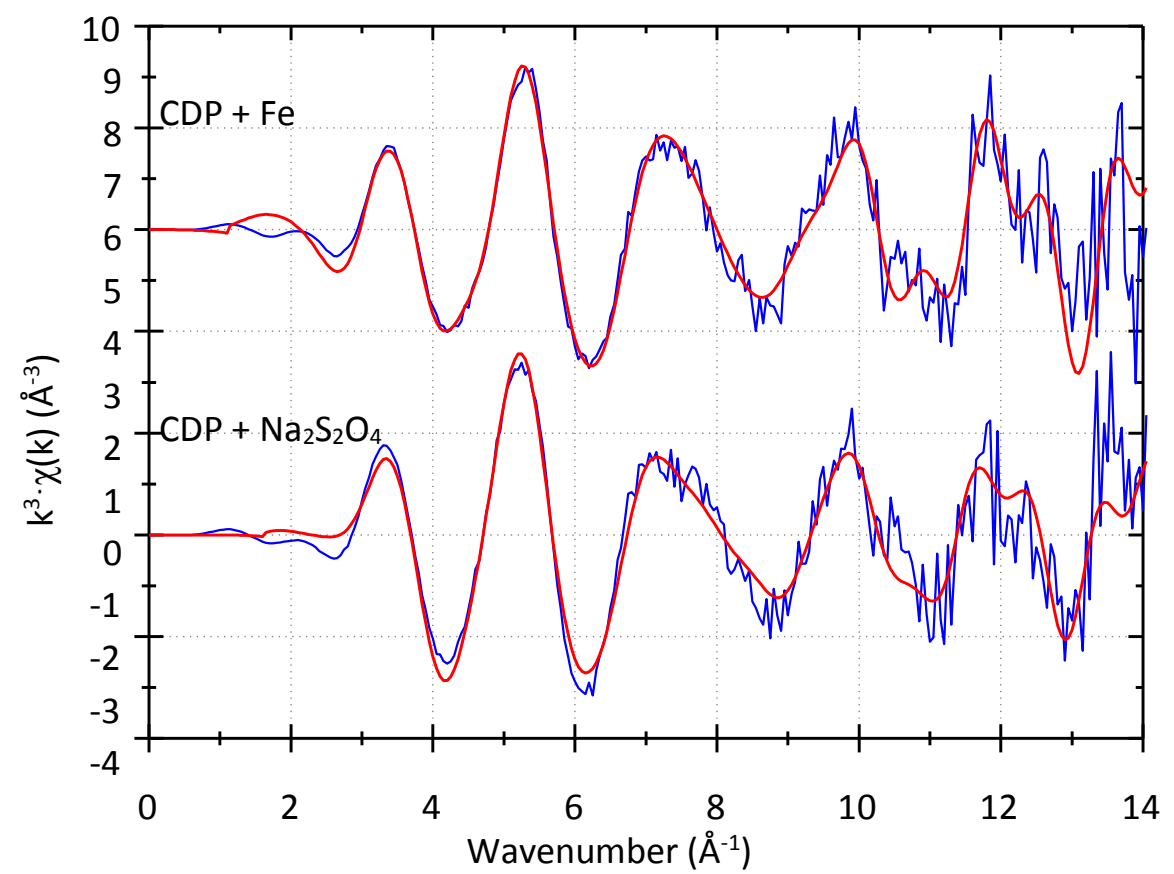

(b)

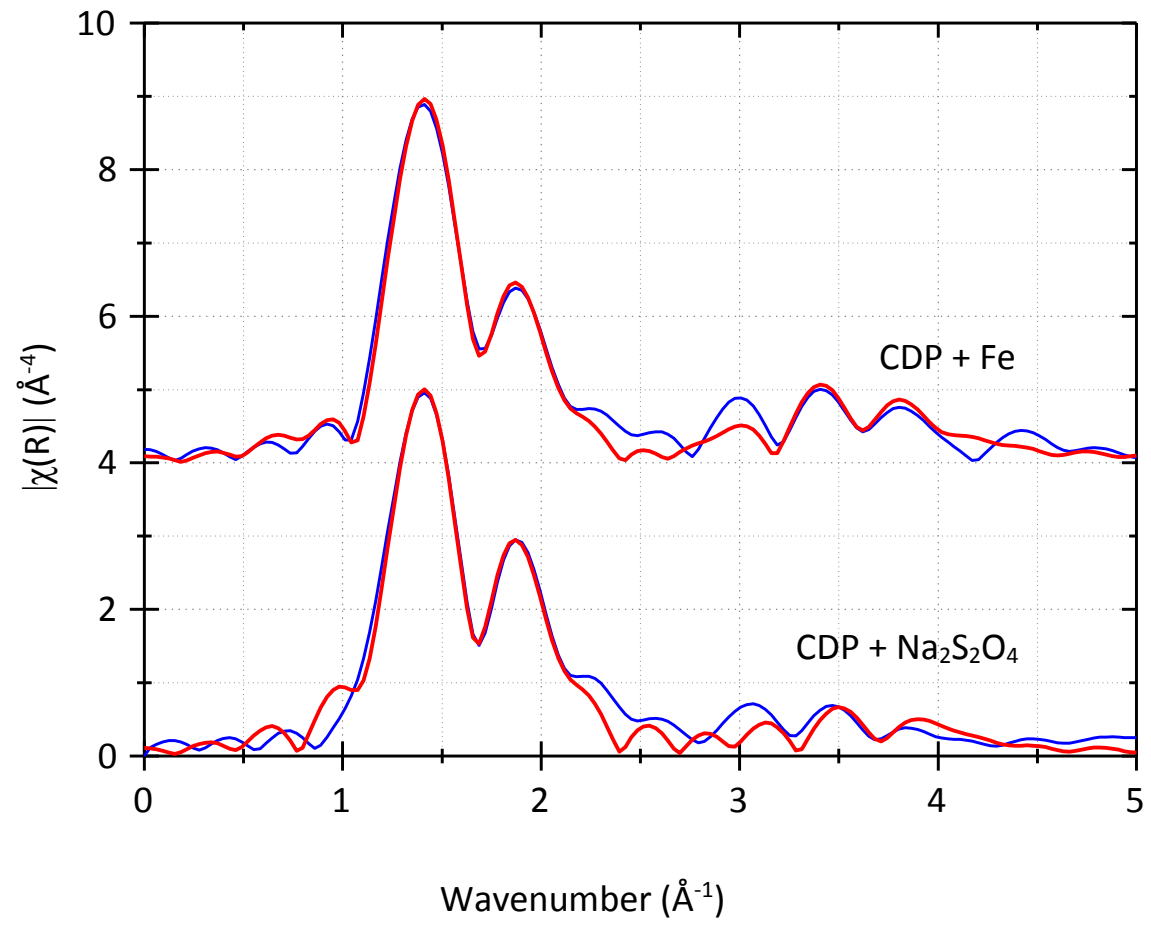

Figure 6 
(a)

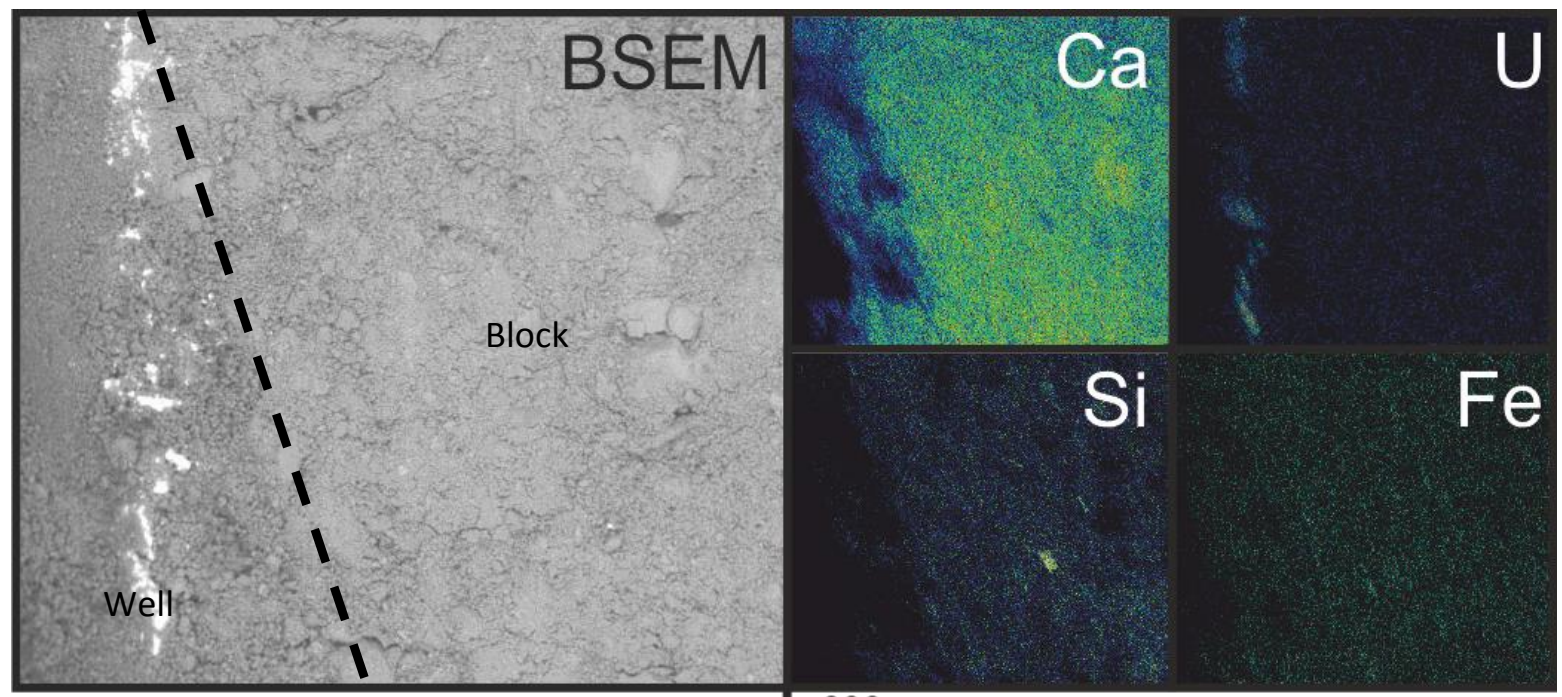

$600 \mu \mathrm{m}$

(b)
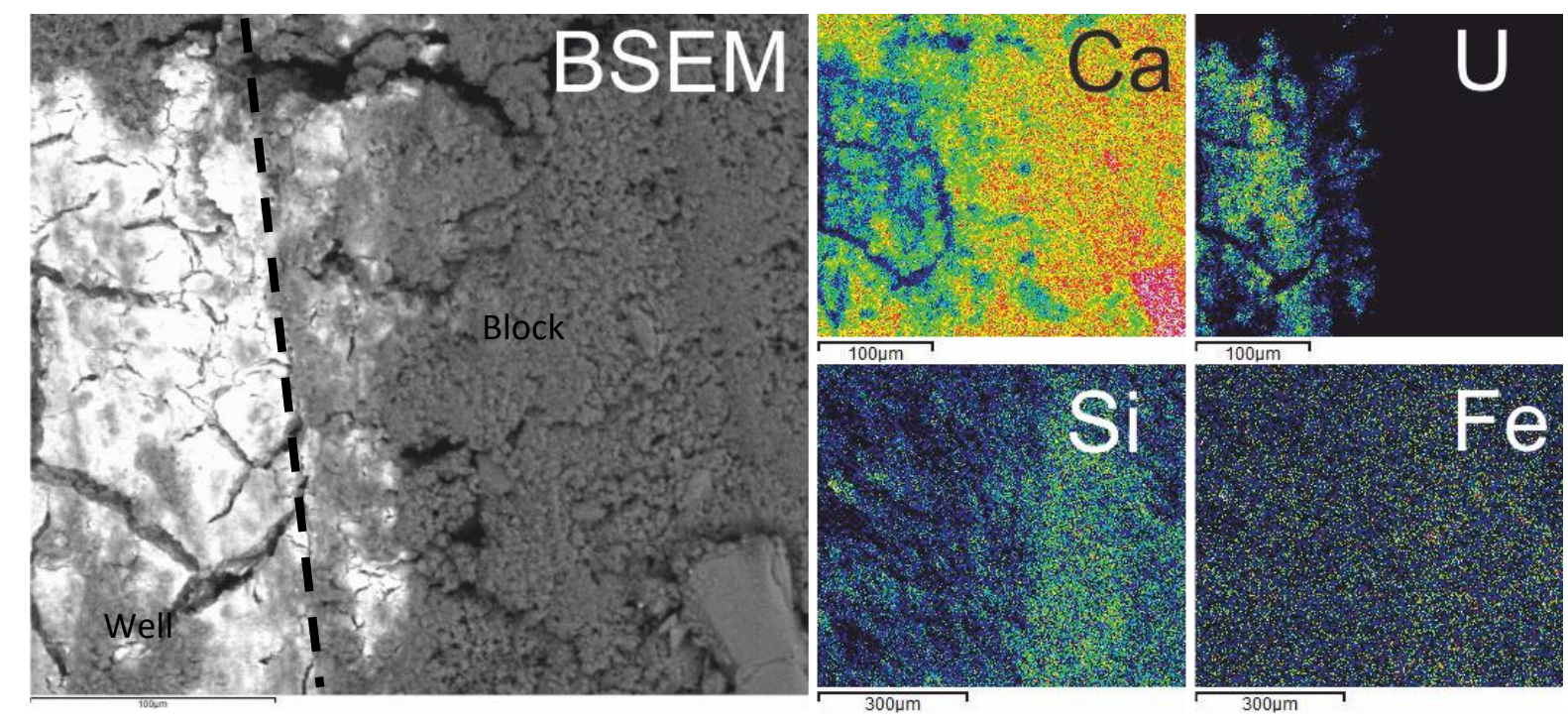

Figure 7 
Table 1.- Composition of the solutions used for the solubility and diffusion experiments

\begin{tabular}{|c|c|c|c|c|}
\hline \multirow[t]{2}{*}{ Composition } & \multicolumn{4}{|c|}{ Solutions } \\
\hline & $\mathrm{NaOH}$ & $\begin{array}{c}\text { 95\%-saturated } \\
\mathrm{Ca}(\mathrm{OH})_{2}\end{array}$ & $\begin{array}{c}\text { NRVB-equilibrated } \\
\text { water }\end{array}$ & CDP \\
\hline $\mathrm{Ca}^{2+}\left(\mathrm{mg} \mathrm{dm}^{-3}\right)$ & $<0.02 *$ & 380 & 462 & 627 \\
\hline $\mathrm{K}^{+}\left(\mathrm{mg} \mathrm{dm} \mathbf{d m}^{-3}\right)$ & $<0.1 *$ & $<0.1 *$ & 358 & 974 \\
\hline $\mathrm{Na}^{+}\left(\mathrm{mg} \mathrm{dm}^{-3}\right)$ & 460 & $<0.1 *$ & 102 & 326 \\
\hline $\mathrm{Cl}^{-}\left(\mathrm{mg} \mathrm{dm}^{-3}\right)$ & N/D & N/D & 23 & 44 \\
\hline $\mathrm{NO}_{3}^{-}\left(\mathrm{mg} \mathrm{dm}^{-3}\right)$ & N/D & N/D & 10 & 9.0 \\
\hline $\mathrm{SO}_{4}{ }^{2-}\left(\mathrm{mg} \mathrm{dm}^{-3}\right)$ & $\mathrm{N} / \mathrm{D}$ & $\mathrm{N} / \mathrm{D}$ & 29 & 173 \\
\hline $\mathrm{Al}\left(\mu \mathrm{g} \mathrm{dm} \mathrm{dm}^{-3}\right)$ & $<0.6^{*}$ & $<0.6^{*}$ & 268 & 208 \\
\hline $\operatorname{Cs}\left(\mu g_{d m}{ }^{-3}\right)$ & $<1.7 *$ & $<1.7 *$ & 4768 & 12609 \\
\hline Eu $\left(\mu \mathrm{g} \mathrm{dm}{ }^{-3}\right)$ & $<1.9 *$ & $<1.9 *$ & $<1.9 *$ & $<1.9 *$ \\
\hline $\mathrm{Li}\left(\mu \mathrm{g} \mathrm{dm}^{-3}\right)$ & $<0.1 *$ & $<0.1 *$ & 1642 & 5983 \\
\hline $\operatorname{Mg}\left(\mu \mathrm{g} \mathrm{dm}^{-3}\right)$ & $<0.1 *$ & $<0.1 *$ & 127 & 46 \\
\hline $\mathrm{Ni}\left(\mu \mathrm{g} \mathrm{dm}^{-3}\right)$ & $<1.3 *$ & $<1.3 *$ & 8.3 & 504 \\
\hline Se $\left(\mu \mathrm{g} \mathrm{dm}^{-3}\right)$ & $<2.3 *$ & $<2.3 *$ & $<2.3 *$ & 5.6 \\
\hline $\operatorname{Sr}\left(\mu \mathrm{g} \mathrm{dm}^{-3}\right)$ & $<0.03^{*}$ & $<0.03^{*}$ & 6495 & 12607 \\
\hline Th $\left(\mu \mathrm{g} \mathrm{dm}^{-3}\right)$ & $<0.1 *$ & $<0.1 *$ & $<0.1^{*}$ & $<0.1^{*}$ \\
\hline $\mathrm{U}\left(\boldsymbol{\mu g} \mathrm{dm}^{-3}\right)$ & $<0.1 *$ & $<0.1 *$ & $<0.1^{*}$ & 0.20 \\
\hline $\begin{array}{c}\text { TIC } \\
\left(\mathrm{mg} \mathrm{dm}^{-3} \text { as } \mathrm{CO}_{3}{ }^{2-}\right)\end{array}$ & $<0.5^{*}$ & $<0.5^{*}$ & 2.5 & 4.8 \\
\hline $\begin{array}{c}\text { TOC } \\
\left(\mathrm{mg} \mathrm{dm}^{-3} \text { as C) }\right.\end{array}$ & $<0.5^{*}$ & $<0.5^{*}$ & 3.4 & 187 \\
\hline \multicolumn{5}{|c|}{ Analysis of organics in CDP } \\
\hline & & & ISA $\left(\mathrm{mmol} \mathrm{dm}^{-3}\right)$ & 0.41 \\
\hline & & & Lactate $\left(\mathrm{mmol} \mathrm{dm}^{-3}\right)$ & 2.0 \\
\hline & & & Formate $\left(\mathrm{mmol} \mathrm{dm}^{-3}\right)$ & 1.9 \\
\hline & & & Acetate $\left(\mathrm{mmol} \mathrm{dm}^{-3}\right)$ & 0.66 \\
\hline
\end{tabular}

* LOD

\# Against standard hydrogen electrode (SHE)

N/D not determined 
Table 2-. Evolution of $\mathrm{pH}$ and $\mathrm{E}_{\mathrm{h}}$ values during the solubility experiments

\begin{tabular}{|c|c|c|c|c|c|}
\hline \multirow[b]{2}{*}{ Solution } & \multirow[b]{2}{*}{ Experiment } & \multicolumn{2}{|c|}{$\mathbf{p H}$} & \multicolumn{2}{|c|}{$\mathbf{E h}_{h}^{\#}(\mathbf{m V})$} \\
\hline & & $\begin{array}{l}\text { Initial } \\
\text { (day 0) }\end{array}$ & $\begin{array}{c}\text { Final } \\
(\text { day 1340) }\end{array}$ & $\begin{array}{l}\text { Initial } \\
\text { (day 0) }\end{array}$ & $\begin{array}{c}\text { Final } \\
\text { (day 1340) }\end{array}$ \\
\hline \multirow[t]{2}{*}{$0.02 \mathrm{M} \mathrm{NaOH}$} & Over-saturation & 12.5 & 12.4 & +325 & -47 \\
\hline & Under-saturation & 12.5 & 12.4 & +325 & -27 \\
\hline \multirow{2}{*}{$\begin{array}{l}\text { 95\%-saturated } \\
\mathrm{Ca}(\mathrm{OH})_{2}\end{array}$} & Over-saturation & 12.6 & 12.3 & +299 & +10 \\
\hline & Under-saturation & 12.6 & 12.5 & +299 & +10 \\
\hline \multirow{2}{*}{$\begin{array}{l}\text { NRVB-equilibrated } \\
\text { water }\end{array}$} & Over-saturation & 12.9 & 12.4 & +281 & -56 \\
\hline & Under-saturation & 12.9 & 12.7 & +281 & -50 \\
\hline \multirow[t]{2}{*}{ CDP (in NRVB) } & Over-saturation & 12.8 & 12.3 & +247 & -38 \\
\hline & Under-saturation & 12.7 & 12.5 & +246 & -28 \\
\hline \multirow[t]{2}{*}{$\mathrm{CDP}+0.03 \mathrm{M} \mathrm{Na}_{2} \mathrm{~S}_{2} \mathrm{O}_{4}$} & Over-saturation & 12.7 & 11.8 & -557 & -299 \\
\hline & Under-saturation & 12.7 & 12.2 & -557 & -321 \\
\hline \multirow[t]{2}{*}{ CDP + solid Fe } & Over-saturation & 12.7 & 12.3 & +4 & -13 \\
\hline & Under-saturation & 13.0 & 12.8 & +15 & -21 \\
\hline
\end{tabular}

\# Against standard hydrogen electrode (SHE) 
Table 3.- Summary of the solubility values obtained for U(VI) and comparison with published data

\begin{tabular}{|c|c|c|c|}
\hline Liquid medium & Method & [U] (M) & Reference \\
\hline $0.02 \mathrm{M} \mathrm{NaOH}$ & Over-saturation & $1.9 \times 10^{-6}$ & This work $^{\mathrm{a}}$ \\
\hline \multirow[t]{2}{*}{$\begin{array}{l}0.01 \mathrm{M} \mathrm{NaOH} \\
(\mathrm{pH}=12-11.6)\end{array}$} & \multirow[t]{2}{*}{ Over-saturation } & $\begin{array}{l}(9.3 \pm 1.4) \times 10^{-5} \\
\text { (after } 0.45 \mu \mathrm{m} \text { filtration) }\end{array}$ & \multirow[t]{2}{*}{$\begin{array}{l}\text { Clacher and Cowper } \\
\text { (2011) }\end{array}$} \\
\hline & & $\begin{array}{l}(1.5 \pm 0.3) \times 10^{-7} \\
(\text { after } 30 \mathrm{kDa} \text { filtration })\end{array}$ & \\
\hline $\begin{array}{l}0.0230-0.0199 \mathrm{~mol} / \mathrm{kg} \\
\mathrm{NaOH}\end{array}$ & $\begin{array}{l}\text { Under-saturation } \\
\mathrm{UO}_{3} \cdot \mathrm{H}_{2} \mathrm{O}\end{array}$ & $\begin{array}{l}(4.45-7.9) \times 10^{-5} \\
\mathrm{~mol} / \mathrm{kg}\end{array}$ & Gayer and Leider (1955) \\
\hline $0.02 \mathrm{M} \mathrm{NaOH}$ & Under-saturation & $5.8 \times 10^{-8}$ & This work $^{\mathrm{a}}$ \\
\hline $95 \%$-saturated $\mathrm{Ca}(\mathrm{OH})_{2}$ & Over-saturation & $6.4 \times 10^{-8}$ & This work $^{\mathrm{a}}$ \\
\hline \multirow[t]{2}{*}{$\begin{array}{l}\text { Near saturated } \mathrm{Ca}(\mathrm{OH})_{2}, \\
(\mathrm{pH}=12-11.2)\end{array}$} & \multirow[t]{2}{*}{ Over-saturation } & $\begin{array}{l}(7.0 \pm 5.5) \times 10^{-8} \\
\text { (after } 0.45 \mu \mathrm{m} \text { filtration) }\end{array}$ & \multirow[t]{2}{*}{$\begin{array}{l}\text { Clacher and Cowper } \\
\text { (2011) }\end{array}$} \\
\hline & & $\begin{array}{l}(3.0 \pm 0.6) \times 10^{-7} \\
(\text { after } 30 \mathrm{kDa} \text { filtration })\end{array}$ & \\
\hline \multirow[t]{2}{*}{$\begin{array}{l}\text { Saturated } \mathrm{Ca}(\mathrm{OH})_{2} \mathrm{pH}= \\
12.2\end{array}$} & $\begin{array}{l}\text { Under-saturation } \\
\text { microcrystalline } \mathrm{UO}_{3}\end{array}$ & $5 \times 10^{-7}$ & \multirow[t]{2}{*}{$\begin{array}{l}\text { Valsami-Jones and } \\
\text { Ragnarsdóttir (1997) }\end{array}$} \\
\hline & $\begin{array}{l}\text { Under-saturation } \\
\mathrm{CaU}_{1.6} \mathrm{O}_{5.8} \cdot \mathrm{H}_{2} \mathrm{O}\end{array}$ & $8 \times 10^{-7}$ & \\
\hline $95 \%$-saturated $\mathrm{Ca}(\mathrm{OH})_{2}$ & Under-saturation & $5.2 \times 10^{-9}$ & This work $^{\mathrm{a}}$ \\
\hline $\begin{array}{l}\text { BFS:OPC equilibrated } \\
\text { water }(\mathrm{pH} 13)\end{array}$ & Over-saturation & $10^{-5}$ & Baston et al. (1993) \\
\hline $\begin{array}{l}\text { NRVB equilibrated } \\
\text { water }\end{array}$ & Over-saturation & $4 \times 10^{-6}$ & Greenfield et al. (1997) \\
\hline $\begin{array}{l}\text { NRVB equilibrated } \\
\text { water }\end{array}$ & Over-saturation & $2 \times 10^{-6}$ & Biddle et al. (2000) \\
\hline $\begin{array}{l}\text { NRVB equilibrated } \\
\text { water }\end{array}$ & Over-saturation & $6.3 \times 10^{-8}$ & This work $^{\mathrm{a}}$ \\
\hline $\begin{array}{l}\text { NRVB equilibrated } \\
\text { water }\end{array}$ & Under-saturation & $3.7 \times 10^{-9}$ & This work $^{\mathrm{a}}$ \\
\hline $\begin{array}{l}10 \% \text { cellulose CDP in } \\
\text { NRVB }\end{array}$ & Over-saturation & $1 \times 10^{-4}$ & Greenfield et al. (1997) \\
\hline $\begin{array}{l}1 \% \text { cellulose CDP in } \\
\text { NRVB }\end{array}$ & Over-saturation & $2 \times 10^{-5}$ & Biddle et al. (2000) \\
\hline CDP in $\mathrm{NRVB}^{\mathrm{b}}$ & Over-saturation & $1.5 \times 10^{-6}$ & This work ${ }^{\mathrm{a}}$ \\
\hline CDP in $\mathrm{NRVB}^{\mathrm{b}}$ & Under-saturation & $3.0 \times 10^{-8}$ & This work ${ }^{\mathrm{a}}$ \\
\hline
\end{tabular}

${ }^{a}$ Final results after 1340 days equilibration

b $5 \%$ cellulose load; $187 \mathrm{mg} / \mathrm{L}$ TOC

${ }^{\mathrm{c}}$ From graph 
Table 4.- Summary of the solubility values obtained for U(IV) and comparison with published data

\begin{tabular}{|c|c|c|c|c|}
\hline Liquid medium & Holding reagent & Method & [U] (M) & Reference \\
\hline $\begin{array}{l}\mathrm{NaOH} \mathrm{pH}=12.36 / \\
0.5 \mathrm{M} \mathrm{HClO}_{4}\end{array}$ & $\mathrm{Na}_{2} \mathrm{~S}_{2} \mathrm{O}_{4}$ & Over-saturation & $2.59 \times 10^{-8}$ & $\begin{array}{l}\text { Fujiwara et al. } \\
\text { (2005) }\end{array}$ \\
\hline $\begin{array}{l}\text { BFS:OPC equilibrated } \\
\text { water }(\mathrm{pH}>10.5)\end{array}$ & $0.05 \mathrm{M} \mathrm{Na}_{2} \mathrm{~S}_{2} \mathrm{O}_{4}$ & Over-saturation & $3 \times 10^{-7}$ & Baston et al. (1993) \\
\hline NRVB equilibrated water & $\mathrm{Na}_{2} \mathrm{~S}_{2} \mathrm{O}_{4}$ & Over-saturation & $8 \times 10^{-7}$ & $\begin{array}{l}\text { Greenfield et al. } \\
\text { (1997) }\end{array}$ \\
\hline $\begin{array}{l}\text { BFS:OPC equilibrated } \\
\text { water }(\mathrm{pH} 12.3)\end{array}$ & $0.05 \mathrm{M} \mathrm{Na}_{2} \mathrm{~S}_{2} \mathrm{O}_{4}$ & Under-saturation & $2 \times 10^{-7}$ & Baston et al. (1993) \\
\hline $\begin{array}{l}10 \% \text { cellulose CDP in } \\
\text { NRVB }\end{array}$ & $\mathrm{Na}_{2} \mathrm{~S}_{2} \mathrm{O}_{4}$ & Over-saturation & $1 \times 10^{-4}$ & $\begin{array}{l}\text { Greenfield et al. } \\
\text { (1997) }\end{array}$ \\
\hline $\mathrm{CDP}$ in $\mathrm{NRVB}^{\mathrm{b}}$ & $0.03 \mathrm{M} \mathrm{Na}_{2} \mathrm{~S}_{2} \mathrm{O}_{4}$ & Over-saturation & $8.2 \times 10^{-7}$ & This work $^{\mathrm{a}}$ \\
\hline CDP in NRVB ${ }^{b}$ & $0.03 \mathrm{M} \mathrm{Na}_{2} \mathrm{~S}_{2} \mathrm{O}_{4}$ & Under-saturation & $1.8 \times 10^{-7}$ & This work $^{\mathrm{a}}$ \\
\hline
\end{tabular}

${ }^{a}$ Final results after 1340 days equilibration

b $5 \%$ cellulose load; $187 \mathrm{mg} / \mathrm{L}$ TOC 
Table 5 - Summary of the solubility values obtained for Th and comparison with published data

\begin{tabular}{|c|c|c|c|}
\hline Liquid medium & Method & [Th] (M) & Reference \\
\hline $0.02 \mathrm{M} \mathrm{NaOH}$ & Over-saturation & $5.8 \times 10^{-10}$ & This work $^{\mathrm{a}}$ \\
\hline $0.02 \mathrm{M} \mathrm{NaOH}$ & Under-saturation & $2.8 \times 10^{-9}$ & This work $^{\mathrm{a}}$ \\
\hline $0.5 \mathrm{M} \mathrm{NaCl} / 0.02 \mathrm{M} \mathrm{NaOH}$ & $\begin{array}{l}\text { Under-saturation } \\
\left(\mathrm{ThO}_{2(\mathrm{am})}\right)\end{array}$ & $6.6 \times 10^{-7}-1.8 \times 10^{-9}$ & Neck et al. (2002) \\
\hline $\begin{array}{l}0.5 \mathrm{M} \mathrm{NaCl} / \mathrm{NaOH}(\mathrm{pH} 11.0- \\
13.5)\end{array}$ & $\begin{array}{l}\text { Under-saturation } \\
\left(\mathrm{ThO}_{2(\mathrm{cr})}\right)\end{array}$ & $5 \times 10^{-10}$ & Neck et al. (2003) \\
\hline $\begin{array}{l}0.1-0.5 \mathrm{M} \mathrm{NaCl} / \mathrm{NaClO}_{4} \\
(\mathrm{pH}=6-14)\end{array}$ & $\begin{array}{l}\text { Under-saturation } \\
\left(\mathrm{ThO}_{2} \cdot \mathrm{xH}_{2} \mathrm{O}\right)\end{array}$ & $3.2 \times 10^{-9}$ & Brendebach et al. (2007) \\
\hline $95 \%$-saturated $\mathrm{Ca}(\mathrm{OH})_{2}$ & Over-saturation & $8.0 \times 10^{-9}$ & This work $^{\mathrm{a}}$ \\
\hline $95 \%$-saturated $\mathrm{Ca}(\mathrm{OH})_{2}$ & Under-saturation & $2.8 \times 10^{-9}$ & This work $^{\mathrm{a}}$ \\
\hline $\begin{array}{l}\text { BFS:OPC:limestone } \\
\text { equilibrated water }\end{array}$ & Over-saturation & $4 \times 10^{-9}$ & $\begin{array}{l}\text { Ewart et al. (1992); } \\
\text { Thomason and Williams } \\
\text { (1992) }\end{array}$ \\
\hline NRVB equilibrated water & Over-saturation & $<2 \times 10^{-10}$ & Greenfield et al. (1997) \\
\hline OPC squeezed pore water & Over-saturation & $7.1 \times 10^{-10}-2.4 \times 10^{-8}$ & Kitamura et al (2013) \\
\hline NRVB equilibrated water & Over-saturation & $1.6 \times 10^{-10}$ & This work $^{\mathrm{a}}$ \\
\hline $\begin{array}{l}\text { CEM I } 42.5 \text { HS equilibrated } \\
\text { water }(\mathrm{pH} 12.45)\end{array}$ & $\begin{array}{l}\text { Under-saturation } \\
\left(\mathrm{ThO}_{2 \text { (microcr) })}\right.\end{array}$ & $10^{-10}-10^{-9}$ & Wierczinski et al (1998) \\
\hline NRVB equilibrated water & Under-saturation & $3.3 \times 10^{-10}$ & This work $^{\mathrm{a}}$ \\
\hline $10 \%$ cellulose CDP in NRVB & Over-saturation & $2 \times 10^{-6}$ & Greenfield et al. (1997) \\
\hline $1 \%$ cellulose CDP in NRVB & Over-saturation & $10^{-8}$ & Biddle et al. (2000) \\
\hline $\mathrm{CDP}$ in $\mathrm{NRVB}^{\mathrm{b}}$ & Over-saturation & $7.3 \times 10^{-8}$ & This work $^{\mathrm{a}}$ \\
\hline $\begin{array}{l}4 \times 10^{-4} \mathrm{~mol} / \mathrm{kg} \mathrm{ISA} \text { at } \mathrm{pH} \\
12.01(\mathrm{NaOH} / \mathrm{HCl})\end{array}$ & $\begin{array}{l}\text { Under-saturation } \\
\left(\mathrm{ThO}_{2(\mathrm{am})}\right)\end{array}$ & $1.6 \times 10^{-9} \mathrm{~mol} / \mathrm{kg}$ & Biddle et al. (2000) \\
\hline CDP in $N_{R V B}{ }^{b}$ & Under-saturation & $2.7 \times 10^{-9}$ & This work ${ }^{\mathrm{a}}$ \\
\hline
\end{tabular}

${ }^{\mathrm{a}}$ Final results after 1340 days equilibration

b $5 \%$ cellulose load; $187 \mathrm{mg} / \mathrm{L}$ TOC 
Table 6 - EXAFS best fit parameters for the uranium precipitates generated in the CDP solutions in the presence of reducing agents

\begin{tabular}{|c|c|c|c|c|c|c|c|c|c|}
\hline & \multicolumn{3}{|c|}{$\mathrm{CDP}$ in $\mathrm{NRVB}$ with $\mathrm{Na}_{2} \mathrm{~S}_{2} \mathrm{O}_{4}$} & \multicolumn{3}{|c|}{ CDP in NRVB with solid Fe } & \multicolumn{3}{|c|}{ Becquerelite* } \\
\hline & $\mathbf{N}$ & $\mathbf{R} / \mathbf{A}$ & $\sigma^{2}$ & $\mathbf{N}$ & $\mathbf{R} / \mathbf{A}$ & $\sigma^{2}$ & & FS R/Å & XRD R/Å \\
\hline \multirow{2}{*}{$\mathrm{U}-\mathrm{O}_{\mathrm{ax}}$} & \multirow{2}{*}{2} & \multirow{2}{*}{1.73} & \multirow{2}{*}{0.0035} & \multirow{2}{*}{2} & \multirow{2}{*}{1.8} & \multirow{2}{*}{0.0036} & $\mathrm{U}-\mathrm{O}_{\mathrm{ax} 1}$ & $1.745 \pm 0.027$ & 1.7699 \\
\hline & & & & & & & $\mathrm{U}-\mathrm{O}_{\mathrm{ax} 2}$ & $1.826 \pm 0.018$ & 1.8036 \\
\hline \multirow[t]{2}{*}{ U-O $\mathrm{O}_{\text {eq } 1}$} & \multirow[t]{2}{*}{2.5} & \multirow[t]{2}{*}{1.91} & \multirow[t]{2}{*}{0.0011} & \multirow[t]{2}{*}{2.5} & \multirow[t]{2}{*}{2.42} & \multirow[t]{2}{*}{0.0074} & $\mathrm{U}-\mathrm{O}_{\mathrm{eq}}$ & $2.100 \pm 0.062$ & 2.2289 \\
\hline & & & & & & & $\mathrm{U}-\mathrm{OH}_{\mathrm{eq} 1}$ & $2.468 \pm 0.095$ & 2.6464 \\
\hline \multirow[t]{2}{*}{$\mathrm{U}-\mathrm{O}_{\mathrm{eq} 2}$} & \multirow[t]{2}{*}{2.5} & \multirow[t]{2}{*}{2.16} & \multirow[t]{2}{*}{0.0006} & \multirow[t]{2}{*}{2.5} & \multirow[t]{2}{*}{2.32} & \multirow[t]{2}{*}{0.0100} & $\mathrm{U}-\mathrm{OH}_{\mathrm{eq} 2}$ & $2.336 \pm 0.095$ & 2.515 \\
\hline & & & & & & & $\mathrm{U}-\mathrm{OH}_{\mathrm{eq} 3}$ & $2.207 \pm 0.095$ & 2.3853 \\
\hline $\mathrm{U}-\mathrm{U}_{1}$ & 2 & 3.59 & 0.0017 & 2 & 3.76 & 0.0075 & $\mathrm{U}-\mathrm{U}_{1}$ & $4.426 \pm 0.301$ & 3.8085 \\
\hline $\mathrm{U}-\mathrm{U}_{2}$ & 2 & 3.94 & 0.0037 & 2 & 3.94 & 0.0140 & $\mathrm{U}-\mathrm{U}_{2}$ & $4.461 \pm 0.301$ & 3.8438 \\
\hline U-Ca & 1 & 4.21 & 0.0100 & 1 & 4.09 & 0.0016 & --- & --- & --- \\
\hline $\mathrm{U}-\mathrm{O}_{\text {uraninite }}$ & 8 & 2.37 & 0.0076 & --- & --- & --- & --- & --- & --- \\
\hline $\mathbf{S O}^{2}$ & \multicolumn{3}{|c|}{0.754} & \multicolumn{3}{|c|}{1.15} & \multirow{4}{*}{\multicolumn{3}{|c|}{$\begin{array}{l}\text { * Data from } \\
\text { Burciaga-Valencia et al. (2010) }\end{array}$}} \\
\hline EO & & \multicolumn{3}{|c|}{9.42} & & & \\
\hline Reduced $\chi^{2}$ & \multicolumn{3}{|c|}{3.77} & \multicolumn{3}{|c|}{3.29} & & & \\
\hline $\mathbf{R}$ & \multicolumn{3}{|c|}{0.017} & \multicolumn{3}{|c|}{0.036} & & & \\
\hline
\end{tabular}


Table 7.- EXAFS best fit parameters for the uranium precipitates deposited in central well of the NRVB blocks used for diffusion with and without CDP

\begin{tabular}{|c|c|c|c|c|c|c|}
\hline & \multicolumn{3}{|c|}{ NRVB } & \multicolumn{3}{|c|}{ CDP in NRVB } \\
\hline & $\mathbf{N}$ & $\mathbf{R} / \AA$ & $\sigma^{2}$ & $\mathbf{N}$ & $\mathbf{R} / \AA$ & $\sigma^{2}$ \\
\hline $\mathrm{U}-\mathrm{O}_{\mathrm{ax}}$ & 2 & 1.79 & 0.0005 & 2 & 1.81 & 0.0024 \\
\hline $\mathrm{U}-\mathrm{O}_{\mathrm{eq} 1}$ & 3 & 2.40 & 0.0057 & 3 & 2.45 & 0.0031 \\
\hline $\mathrm{U}-\mathrm{O}_{\mathrm{eq} 2}$ & 2 & 2.25 & 0.0032 & 2 & 2.39 & 0.0016 \\
\hline U-U $U_{1}$ & 3 & 3.78 & 0.0110 & 3 & 3.86 & 0.0031 \\
\hline $\mathrm{U}-\mathrm{U}_{2}$ & 1 & 3.62 & 0.0028 & 1 & 3.70 & 0.0030 \\
\hline U-Ca & 1 & 4.01 & 0.0050 & 1 & 4.08 & 0.0071 \\
\hline $\mathrm{SO}^{2}$ & \multicolumn{3}{|c|}{1.00} & \multicolumn{3}{|c|}{0.64} \\
\hline E0 & \multicolumn{3}{|c|}{4.87} & \multicolumn{3}{|c|}{9.93} \\
\hline Reduced $\chi^{2}$ & \multicolumn{3}{|c|}{30.70} & \multicolumn{3}{|c|}{39.48} \\
\hline $\mathbf{R}$ & \multicolumn{3}{|c|}{0.012} & \multicolumn{3}{|c|}{0.017} \\
\hline
\end{tabular}

4

5 
Table S1.- Overview of the reactions and thermodynamic equilibrium constants used in this study

\begin{tabular}{|c|c|c|c|}
\hline Species & Reaction & $\log K$ & Reference \\
\hline \multicolumn{4}{|l|}{ Thorium } \\
\hline $\mathrm{Th}(\mathrm{OH})^{3+}$ & $\mathrm{Th}^{4+}+\mathrm{H}_{2} \mathrm{O} \leftrightarrow \mathrm{Th}(\mathrm{OH})^{3+}+\mathrm{H}^{+}$ & -2.50 & HATCHES 20 \\
\hline $\mathrm{Th}(\mathrm{OH})_{2}{ }^{2+}$ & $\mathrm{Th}^{4+}+2 \mathrm{H}_{2} \mathrm{O} \leftrightarrow \mathrm{Th}(\mathrm{OH})_{2}^{2+}+2 \mathrm{H}^{+}$ & -6.20 & HATCHES 20 \\
\hline $\mathrm{Th}(\mathrm{OH})_{4}$ & $\mathrm{Th}^{4+}+4 \mathrm{H}_{2} \mathrm{O} \leftrightarrow \mathrm{Th}(\mathrm{OH})_{4}+4 \mathrm{H}^{+}$ & -17.40 & HATCHES 20 \\
\hline $\mathrm{Th}_{2}(\mathrm{OH})_{2}{ }^{6+}$ & $2 \mathrm{Th}^{4+}+2 \mathrm{H}_{2} \mathrm{O} \leftrightarrow \mathrm{Th}_{2}(\mathrm{OH})_{2}{ }^{6+}+2 \mathrm{H}^{+}$ & -5.90 & HATCHES 20 \\
\hline $\mathrm{Th}_{2}(\mathrm{OH})_{3}^{5+}$ & $2 \mathrm{Th}^{4+}+3 \mathrm{H}_{2} \mathrm{O} \leftrightarrow \mathrm{Th}_{2}(\mathrm{OH})_{3}{ }^{5+}+3 \mathrm{H}^{+}$ & -6.80 & HATCHES 20 \\
\hline $\mathrm{Th}_{4}(\mathrm{OH})_{12}{ }^{4+}$ & $4 \mathrm{Th}^{4+}+12 \mathrm{H}_{2} \mathrm{O} \leftrightarrow \mathrm{Th}_{4}(\mathrm{OH})_{12}{ }^{4+}+12 \mathrm{H}^{+}$ & -26.60 & HATCHES 20 \\
\hline $\mathrm{Th}_{4}(\mathrm{OH})_{8}^{8+}$ & $4 \mathrm{Th}^{4+}+8 \mathrm{H}_{2} \mathrm{O} \leftrightarrow \mathrm{Th}_{4}(\mathrm{OH})_{8}^{8+}+8 \mathrm{H}^{+}$ & -20.40 & HATCHES 20 \\
\hline $\mathrm{Th}_{6}(\mathrm{OH})_{14}{ }^{10+}$ & $6 \mathrm{Th}^{4+}+14 \mathrm{H}_{2} \mathrm{O} \leftrightarrow \mathrm{Th}_{6}(\mathrm{OH})_{14}{ }^{10+}+14 \mathrm{H}^{+}$ & -36.80 & HATCHES 20 \\
\hline $\mathrm{Th}_{6}(\mathrm{OH})_{15^{9+}}$ & $6 \mathrm{Th}^{4+}+15 \mathrm{H}_{2} \mathrm{O} \leftrightarrow \mathrm{Th}_{6}(\mathrm{OH})_{15}{ }^{9+}+15 \mathrm{H}^{+}$ & -36.80 & HATCHES 20 \\
\hline $\operatorname{Th}(\mathrm{ISA})^{-}$ & $\mathrm{Th}^{4+}+\mathrm{ISA}^{5-} \leftrightarrow \mathrm{Th}(\mathrm{ISA})^{-}$ & -10.50 & HATCHES 20 \\
\hline $\mathrm{Th}\left(\mathrm{H}_{2} \mathrm{ISA}\right)_{2} \mathrm{Ca}^{-}$ & $\mathrm{Th}^{4+}+2 \mathrm{H}_{4} \mathrm{ISA}^{-}+\mathrm{Ca}^{2+} \leftrightarrow \mathrm{Th}\left(\mathrm{H}_{2} \mathrm{ISA}\right)_{2} \mathrm{Ca}+4 \mathrm{H}^{+}$ & -5.0 & Tits et al. (2005) \\
\hline $\operatorname{Th}(\text { Acetate })^{3+}$ & $\mathrm{Th}^{4+}+$ Acetate $^{-} \leftrightarrow \operatorname{Th}(\text { Acetate })^{3+}$ & -0.57 & HATCHES 20 \\
\hline $\operatorname{Th}(\text { Acetate })_{2}^{2+}$ & $\mathrm{Th}^{4+}+2$ Acetate $^{-} \leftrightarrow \mathrm{Th}(\text { Acetate })_{2}{ }^{2+}$ & -4.47 & HATCHES 20 \\
\hline $\operatorname{Th}(\text { Acetate })_{3}{ }^{+}$ & $\mathrm{Th}^{4+}+3$ Acetate $^{-} \leftrightarrow \mathrm{Th}(\text { Acetate })_{3}{ }^{+}$ & -3.93 & HATCHES 20 \\
\hline $\operatorname{Th}(\text { Acetate })_{4}$ & $\mathrm{Th}^{4+}+4$ Acetate $^{-} \leftrightarrow \mathrm{Th}(\text { Acetate })_{4}$ & -6.06 & HATCHES 20 \\
\hline Th(Acetate) $5^{-}$ & $\mathrm{Th}^{4+}+5$ Acetate $^{-} \leftrightarrow \mathrm{Th}(\text { Acetate })_{5}^{-}$ & -10.10 & HATCHES 20 \\
\hline \multicolumn{4}{|l|}{ Uranium } \\
\hline $\mathrm{UO}_{2}(\mathrm{OH})_{2}$ & $\mathrm{U}^{4+}+4 \mathrm{H}_{2} \mathrm{O} \leftrightarrow \mathrm{UO}_{2}(\mathrm{OH})_{2}+6 \mathrm{H}^{+}+2 \mathrm{e}^{-}$ & -21.19 & HATCHES 20 \\
\hline $\mathrm{UO}_{2}(\mathrm{OH})_{3}^{-}$ & $\mathrm{U}^{4+}+5 \mathrm{H}_{2} \mathrm{O} \leftrightarrow \mathrm{UO}_{2}(\mathrm{OH})_{3}^{-}+7 \mathrm{H}^{+}+2 \mathrm{e}^{-}$ & -29.29 & HATCHES 20 \\
\hline $\mathrm{UO}_{2}(\mathrm{OH})_{4}^{2-}$ & $\mathrm{U}^{4+}+6 \mathrm{H}_{2} \mathrm{O} \leftrightarrow \mathrm{UO}_{2}(\mathrm{OH})_{4}^{2-}+8 \mathrm{H}^{+}+2 \mathrm{e}^{-}$ & -41.44 & HATCHES 20 \\
\hline$\left(\mathrm{UO}_{2}\right)_{2}(\mathrm{OH})_{2}^{2+}$ & $2 \mathrm{U}^{4+}+6 \mathrm{H}_{2} \mathrm{O} \leftrightarrow\left(\mathrm{UO}_{2}\right)_{2}(\mathrm{OH})_{2}^{2+}+10 \mathrm{H}^{+}+4 \mathrm{e}^{-}$ & -23.95 & HATCHES 20 \\
\hline$\left(\mathrm{UO}_{2}\right)_{3}(\mathrm{OH})_{4}{ }^{2+}$ & $3 \mathrm{U}^{4+}+10 \mathrm{H}_{2} \mathrm{O} \leftrightarrow\left(\mathrm{UO}_{2}\right)_{3}(\mathrm{OH})_{4}^{2+}+16 \mathrm{H}^{+}+6 \mathrm{e}^{-}$ & -39.25 & HATCHES 20 \\
\hline$\left(\mathrm{UO}_{2}\right)_{2}(\mathrm{OH})^{3+}$ & $2 \mathrm{U}^{4+}+5 \mathrm{H}_{2} \mathrm{O} \leftrightarrow\left(\mathrm{UO}_{2}\right)_{2}(\mathrm{OH})^{3+}+9 \mathrm{H}^{+}+4 \mathrm{e}^{-}$ & -22.66 & HATCHES 20 \\
\hline$\left(\mathrm{UO}_{2}\right)_{3}(\mathrm{OH})_{5}^{+}$ & $3 \mathrm{U}^{4+}+11 \mathrm{H}_{2} \mathrm{O} \leftrightarrow\left(\mathrm{UO}_{2}\right)_{3}(\mathrm{OH})_{5}{ }^{+}+17 \mathrm{H}^{+}+6 \mathrm{e}^{-}$ & -42.99 & HATCHES 20 \\
\hline$\left(\mathrm{UO}_{2}\right)_{3}(\mathrm{OH})_{7}^{-}$ & $3 \mathrm{U}^{4+}+13 \mathrm{H}_{2} \mathrm{O} \leftrightarrow\left(\mathrm{UO}_{2}\right)_{3}(\mathrm{OH})_{7}^{-}+19 \mathrm{H}^{+}+6 \mathrm{e}^{-}$ & -59.10 & HATCHES 20 \\
\hline$\left(\mathrm{UO}_{2}\right)_{4}(\mathrm{OH})_{7}^{+}$ & $4 \mathrm{U}^{4+}+15 \mathrm{H}_{2} \mathrm{O} \leftrightarrow\left(\mathrm{UO}_{2}\right)_{4}(\mathrm{OH})_{7}^{+}+23 \mathrm{H}^{+}+8 \mathrm{e}^{-}$ & -58.10 & HATCHES 20 \\
\hline $\mathrm{UO}_{2}^{2+}$ & $\mathrm{U}^{4+}+2 \mathrm{H}_{2} \mathrm{O} \leftrightarrow \mathrm{UO}_{2}^{2+}+4 \mathrm{H}^{+}+2 \mathrm{e}^{-}$ & -9.04 & HATCHES 20 \\
\hline $\mathrm{UO}_{2}$ (Acetate) $)^{+}$ & $\mathrm{U}^{4+}+$ Acetate $^{-}+2 \mathrm{H}_{2} \mathrm{O} \leftrightarrow \mathrm{UO}_{2}(\text { Acetate })^{+}+4 \mathrm{H}^{+}+2 \mathrm{e}^{-}$ & -10.76 & HATCHES 20 \\
\hline $\mathrm{UO}_{2}$ (Acetate $)_{2}$ & $\mathrm{U}^{4+}+2$ Acetate $^{-}+2 \mathrm{H}_{2} \mathrm{O} \leftrightarrow \mathrm{UO}_{2}$ (Acetate $)_{2}+4 \mathrm{H}^{+}+2 \mathrm{e}^{-}$ & -13.10 & HATCHES 20 \\
\hline $\mathrm{UO}_{2}$ (Acetate $)_{3}^{-}$ & $\mathrm{U}^{4+}+3$ Acetate $^{-}+2 \mathrm{H}_{2} \mathrm{O} \leftrightarrow \mathrm{UO}_{2}$ (Acetate) $)^{-}+4 \mathrm{H}^{+}+2 \mathrm{e}^{-}$ & -16.40 & HATCHES 20 \\
\hline $\mathrm{UO}_{2}$ (Acetate) $)^{2-}$ & $\mathrm{U}^{4+}+4$ Acetate $^{-}+2 \mathrm{H}_{2} \mathrm{O} \leftrightarrow \mathrm{UO}_{2}$ (Acetate) $4_{4}^{2-}+4 \mathrm{H}^{+}+2 \mathrm{e}^{-}$ & -8.50 & HATCHES 20 \\
\hline $\mathrm{UO}_{2}(\mathrm{ISA})^{3-}$ & $\mathrm{U}^{4+}+\mathrm{H}_{4} \mathrm{ISA}^{-}+2 \mathrm{H}_{2} \mathrm{O} \leftrightarrow \mathrm{UO}_{2}(\mathrm{ISA})^{3-}+8 \mathrm{H}^{+}+2 \mathrm{e}^{-}$ & -36.50 & Baston et al. (2007) \\
\hline $\mathrm{UO}_{2}\left(\mathrm{H}_{4} \mathrm{ISA}\right)^{+}$ & $\mathrm{U}^{4+}+\mathrm{H}_{4} \mathrm{ISA}^{-}+2 \mathrm{H}_{2} \mathrm{O} \leftrightarrow \mathrm{UO}_{2}\left(\mathrm{H}_{4} \mathrm{ISA}\right)^{+}+4 \mathrm{H}^{+}+2 \mathrm{e}^{-}$ & -5.59 & HATCHES 20 \\
\hline $\mathrm{UO}_{2}\left(\mathrm{H}_{4} \mathrm{ISA}\right)_{2}$ & $\mathrm{U}^{4+}+2 \mathrm{H}_{4} \mathrm{ISA}^{-}+2 \mathrm{H}_{2} \mathrm{O} \leftrightarrow \mathrm{UO}_{2}\left(\mathrm{H}_{4} \mathrm{ISA}\right)_{2}+4 \mathrm{H}^{+}+2 \mathrm{e}^{-}$ & -3.00 & HATCHES 20 \\
\hline $\mathrm{UO}_{2}\left(\mathrm{H}_{4} \mathrm{ISA}\right)_{3}^{-}$ & $\mathrm{U}^{4+}+3 \mathrm{H}_{4} \mathrm{ISA}^{-}+2 \mathrm{H}_{2} \mathrm{O} \leftrightarrow \mathrm{UO}_{2}\left(\mathrm{H}_{4} \mathrm{ISA}\right)_{3}+4 \mathrm{H}^{+}+2 \mathrm{e}^{-}$ & -0.98 & HATCHES 20 \\
\hline $\mathrm{U}(\mathrm{OH})^{3+}$ & $\mathrm{U}^{4+}+\mathrm{H}_{2} \mathrm{O} \leftrightarrow \mathrm{U}(\mathrm{OH})^{3+}+\mathrm{H}^{+}$ & -0.54 & HATCHES 20 \\
\hline $\mathrm{U}(\mathrm{OH})_{4}$ & $\mathrm{U}^{4+}+4 \mathrm{H}_{2} \mathrm{O} \leftrightarrow \mathrm{U}(\mathrm{OH})_{4}+4 \mathrm{H}^{+}$ & -10.0 & HATCHES 20 \\
\hline $\mathrm{U}_{6}(\mathrm{OH})_{15}{ }^{9+}$ & $6 \mathrm{U}^{4+}+15 \mathrm{H}_{2} \mathrm{O} \leftrightarrow \mathrm{U}_{6}(\mathrm{OH})_{15}{ }^{9+}+15 \mathrm{H}^{+}$ & -16.90 & HATCHES 20 \\
\hline 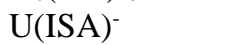 & $\mathrm{U}^{4+}+\mathrm{H}_{4} \mathrm{ISA}^{-} \leftrightarrow \mathrm{U}(\mathrm{ISA})^{-}+4 \mathrm{H}^{+}$ & -5.94 & Baston et al. (2007) \\
\hline $\mathrm{U}(\text { Acetate })^{3+}$ & $\mathrm{U}^{4+}+$ Acetate $^{-} \leftrightarrow \mathrm{U}(\text { Acetate })^{3+}$ & 4.3 & HATCHES 20 \\
\hline $\mathrm{U}(\text { Acetate })_{2}{ }^{2+}$ & $\mathrm{U}^{4+}+2$ Acetate $^{-} \leftrightarrow \mathrm{U}($ Acetate $){ }_{2}{ }^{2+}$ & 10.3 & HATCHES 20 \\
\hline $\mathrm{U}(\text { Acetate })_{3}{ }^{+}$ & $\mathrm{U}^{4+}+3$ Acetate $^{-} \leftrightarrow \mathrm{U}(\text { Acetate })_{3}{ }^{+}$ & 15.4 & HATCHES 20 \\
\hline $\mathrm{U}(\text { Acetate })_{4}$ & $\mathrm{U}^{4+}+4$ Acetate $^{-} \leftrightarrow \mathrm{U}(\text { Acetate })_{4}$ & 19.6 & HATCHES 20 \\
\hline \multicolumn{4}{|l|}{ Calcium } \\
\hline $\mathrm{Ca}\left(\mathrm{H}_{3}\right.$ ISA $)$ & $\mathrm{Ca}^{2+}+\mathrm{H}_{4} \mathrm{ISA}^{-} \leftrightarrow \mathrm{Ca}\left(\mathrm{H}_{3} \mathrm{ISA}\right)+\mathrm{H}^{+}$ & -10.40 & Vercammen et al. (1999) \\
\hline $\mathrm{Ca}\left(\mathrm{H}_{4} \mathrm{ISA}\right)^{+}$ & $\mathrm{Ca}^{2+}+\mathrm{H}_{4} \mathrm{ISA}^{-} \leftrightarrow \mathrm{Ca}\left(\mathrm{H}_{4} \mathrm{ISA}\right)^{+}$ & 1.7 & Tits et al. (2005) \\
\hline
\end{tabular}


Table S1.- Overview of the reactions and thermodynamic equilibrium constants used in this study (continuation)

\begin{tabular}{|c|c|c|c|}
\hline Minerals & Reaction & $\log K_{s p}$ & Reference \\
\hline $\mathrm{ThO}_{2 \text { (am, aged) }}$ & $\mathrm{ThO}_{2}+4 \mathrm{H}^{+} \leftrightarrow \mathrm{Th}^{4+}+2 \mathrm{H}_{2} \mathrm{O}$ & 8.50 & HATCHES 20 \\
\hline $\mathrm{ThO}_{2 \text { (am, fresh) }}$ & $\mathrm{ThO}_{2}+4 \mathrm{H}^{+} \leftrightarrow \mathrm{Th}^{4+}+2 \mathrm{H}_{2} \mathrm{O}$ & 9.30 & HATCHES 20 \\
\hline $\mathrm{Ca}\left(\mathrm{H}_{4} \mathrm{ISA}\right)_{2}$ & $\mathrm{Ca}^{2+}+2 \mathrm{H}_{4} \mathrm{ISA}^{-} \leftrightarrow \mathrm{Ca}\left(\mathrm{H}_{4} \mathrm{ISA}\right)_{2}$ & 6.5 & Van Loon et al. (1999) \\
\hline $\mathrm{CaU}_{2} \mathrm{O}_{7}$ & $\mathrm{CaU}_{2} \mathrm{O}_{7}+14 \mathrm{H}^{+}+4 \mathrm{e}^{-} \leftrightarrow \mathrm{Ca}^{2+}+2 \mathrm{U}^{4+}+7 \mathrm{H}_{2} \mathrm{O}$ & 44.00 & HATCHES 20 \\
\hline $\mathrm{CaUO}_{4}$ & $\mathrm{CaUO}_{4}+4 \mathrm{H}^{+} \leftrightarrow \mathrm{Ca}^{2+}+2 \mathrm{UO}_{2}^{2+}+2 \mathrm{H}_{2} \mathrm{O}$ & $\begin{array}{l}15.90 \\
23.1\end{array}$ & $\begin{array}{l}\text { HATCHES } 20 \\
\text { Moroni and Glasser } \\
(1995)\end{array}$ \\
\hline $\mathrm{Ca}\left(\mathrm{UO}_{2}\right)_{6} \mathrm{O}_{4}(\mathrm{OH})_{6}\left(\mathrm{H}_{2} \mathrm{O}\right)_{6}$ & $\begin{array}{l}\mathrm{Ca}\left(\mathrm{UO}_{2}\right)_{6} \mathrm{O}_{4}(\mathrm{OH})_{6}\left(\mathrm{H}_{2} \mathrm{O}\right)_{6} \leftrightarrow \mathrm{Ca}^{2+}+6 \mathrm{UO}_{2}^{2+}+ \\
18 \mathrm{H}_{2} \mathrm{O}\end{array}$ & 29 & Casas et al. (1997) \\
\hline $\mathrm{Na}_{2} \mathrm{U}_{2} \mathrm{O}_{7}$ & $\mathrm{Na}_{2} \mathrm{U}_{2} \mathrm{O}_{7}+6 \mathrm{H}^{+} \leftrightarrow 2 \mathrm{Na}^{+}+2 \mathrm{UO}_{2}^{2+}+2 \mathrm{H}_{2} \mathrm{O}$ & 22.6 & HATCHES 20 \\
\hline $\mathrm{Na}_{2} \mathrm{U}_{2} \mathrm{O}_{7 \text { (hydr) }}$ & & -29.45 & Yamamura et al. (1998) \\
\hline $\mathrm{Na}_{2} \mathrm{UO}_{4}$ & $\mathrm{Na}_{2} \mathrm{UO}_{4}+4 \mathrm{H}^{+} \leftrightarrow 2 \mathrm{Na}^{+}+\mathrm{UO}_{2}^{2+}+2 \mathrm{H}_{2} \mathrm{O}$ & 31.56 & HATCHES 20 \\
\hline $\mathrm{UO}_{2(\mathrm{am})}$ & $\mathrm{UO}_{2(\mathrm{am})}+4 \mathrm{H}^{+} \leftrightarrow \mathrm{U}^{4+}+2 \mathrm{H}_{2} \mathrm{O}$ & 3.50 & HATCHES 20 \\
\hline
\end{tabular}

\section{References for Table S1}

Baston, G.M.N., Heath, T.G., Hunter, F.M.I., 2008. Summary of additions and amendments to data in the HATCHES chemical thermodynamic database 2002 to 2007. Serco Report, SA/ENV-0934 to Nirex NR3169/010.

HATCHES, version 20, http://www.hatches-database.com

Moroni, L.P., Glasser, F.P, 1995. Reactions between cement components and U(VI) oxide. Waste Manage. 15, 243-254.

Tits, J., Wieland, E., Bradbury, M.H., 2005.The effect of isosaccharinic acid and gluconic acid on the retention of $\mathrm{Eu}(\mathrm{III}), \mathrm{Am}(\mathrm{III})$ and Th(IV) by calcite. App. Geochem. 20, 2082-2096.

Van Loon, L.R., Glaus, M.A., Vercammen, K., 1999, Solubility products of calcium isosaccharinate and calcium gluconate. Acta Chem. Scan. 53. 235-240.

30 Vercammen, K., Glaus, M.A., Van Loon, L.R., 1999. Evidence for the existence of complexes

31 between Th(IV) and $\alpha$-isisaccharinic acid under alkaline conditions. Radiochim. Acta. 84, 221-224.

32 Yamamura, T., Kitamura, A., Fukui, A., Nishikawa, S., Yamamoto, T., Moriyama, H., 1998.

33 Solubility of U(VI) in highly basic solutions. Radiochim. Acta. 83, 139-146. 


\section{Supplementary information: Figure captions}

36 Figure S1.- Powder XRD patterns for the solid phases produced in the under-saturation experiments;

37 (a) in a $0.02 \mathrm{M} \mathrm{NaOH}$ and (b) NRVB-equilibrated water. To obtain the XRD patterns, the precipitates 38 were suspended in acetone (HPLC grade), homogenised with agate pestle and mortar and smeared on 39 a silicon wafer. The acetone was left to evaporate under $\mathrm{N}_{2}$ atmosphere and the resulting thin layer of 40 precipitate was covered with adhesive Mylar® before performing the analyses. Powder XRD data 41 were collected using a Bruker D8 Advance diffractometer in reflection geometry, $\mathrm{Cu} \mathrm{K} \alpha 1$ radiation 42 and a linear position sensitive detector. For phase identification, data were collected over the range 5$4390^{\circ} 2 \theta$ with a step size of $0.007^{\circ}$ and a count time of $0.1 \mathrm{~s}$.

44 Figure S2.- BSEM image showing the U-rich precipitate forming a thin coating on the walls of the 45 central well of the NRVB block used for the diffusion of U(VI) in the absence of CDP.

46 Figure S3.- BSEM images showing the Th-rich precipitates collected in the central well of the NRVB 47 diffusion block used in the absence of CDP with; (a) gel-like and (b) dendritic morphologies.

48 Figure S4.- BSEM image showing the Th-rich precipitates collected in the central well of the NRVB 49 diffusion block used in the presence of CDP.

50 Figure S5- Backscattering images and EDXA elemental mapping of the edge of the central well of 51 the NRVB blocks used in the diffusion of Th: (a) without CDP and (b) with CDP. 
53

54

55

56

57

58

59

60

61

62

63

64

65

66

67

68

69

70

71

72

73

74

75

76

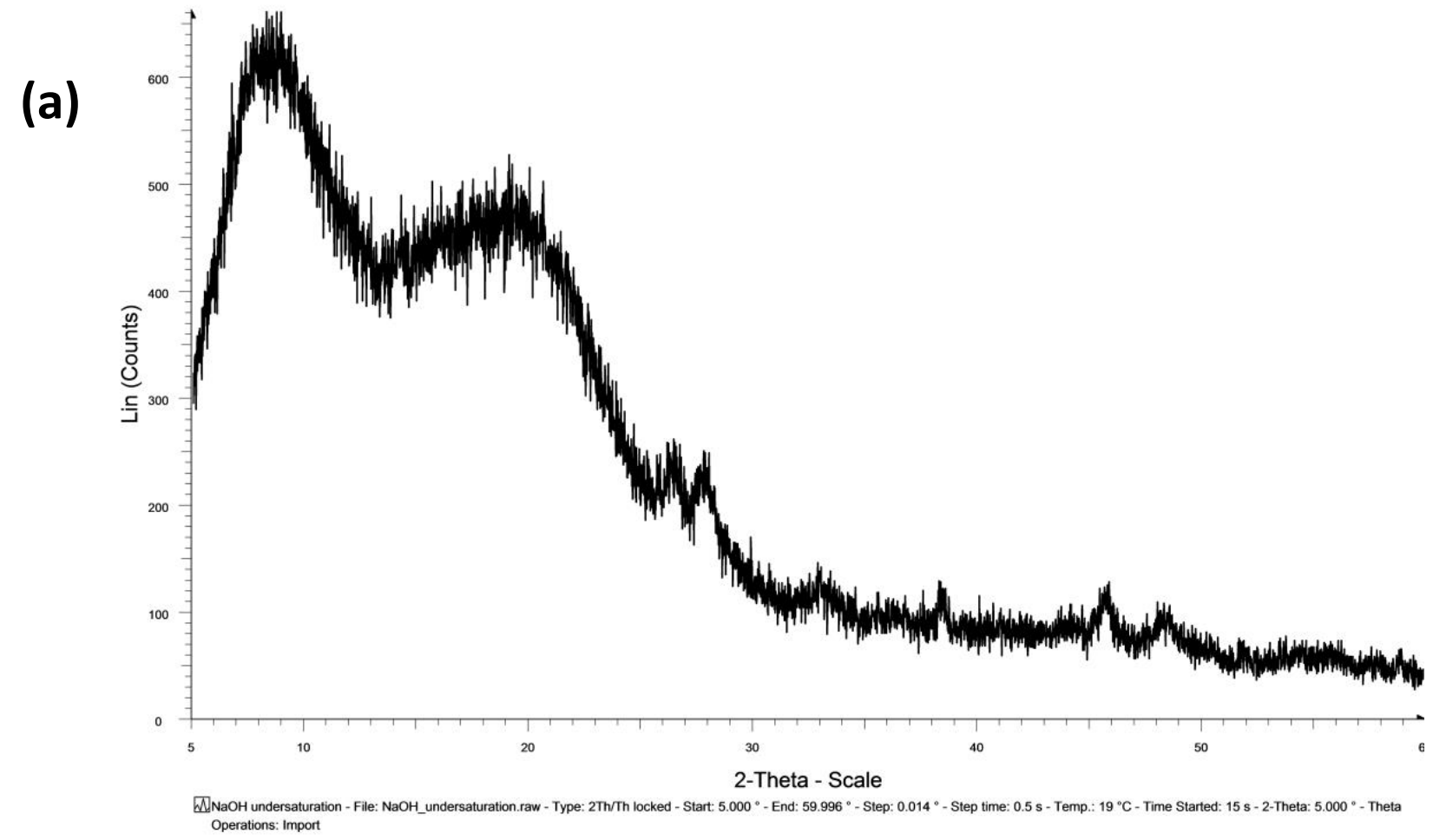

(b)

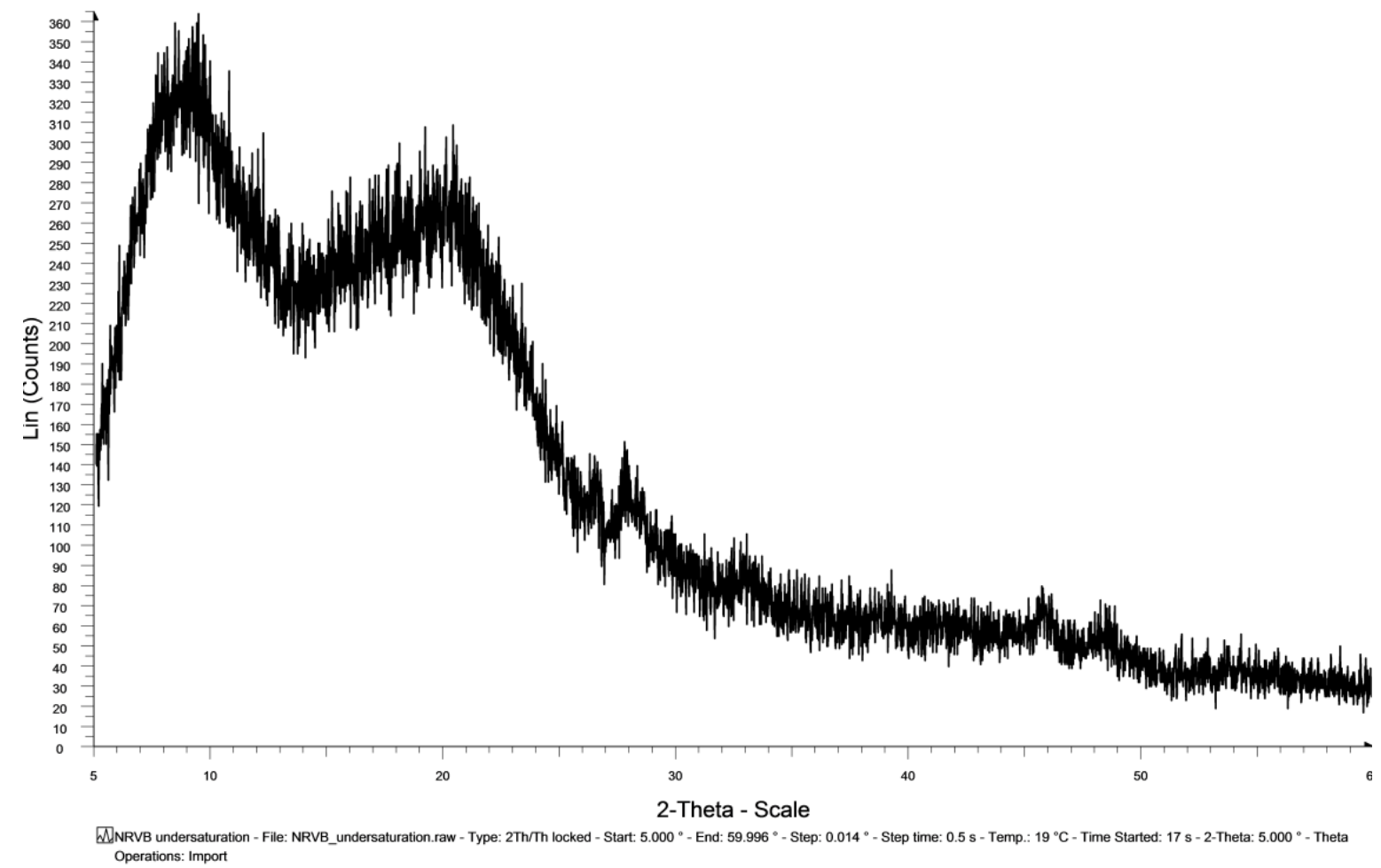

Figure S1 
87

88

89

90

91

92

93

94

95

96

97

98

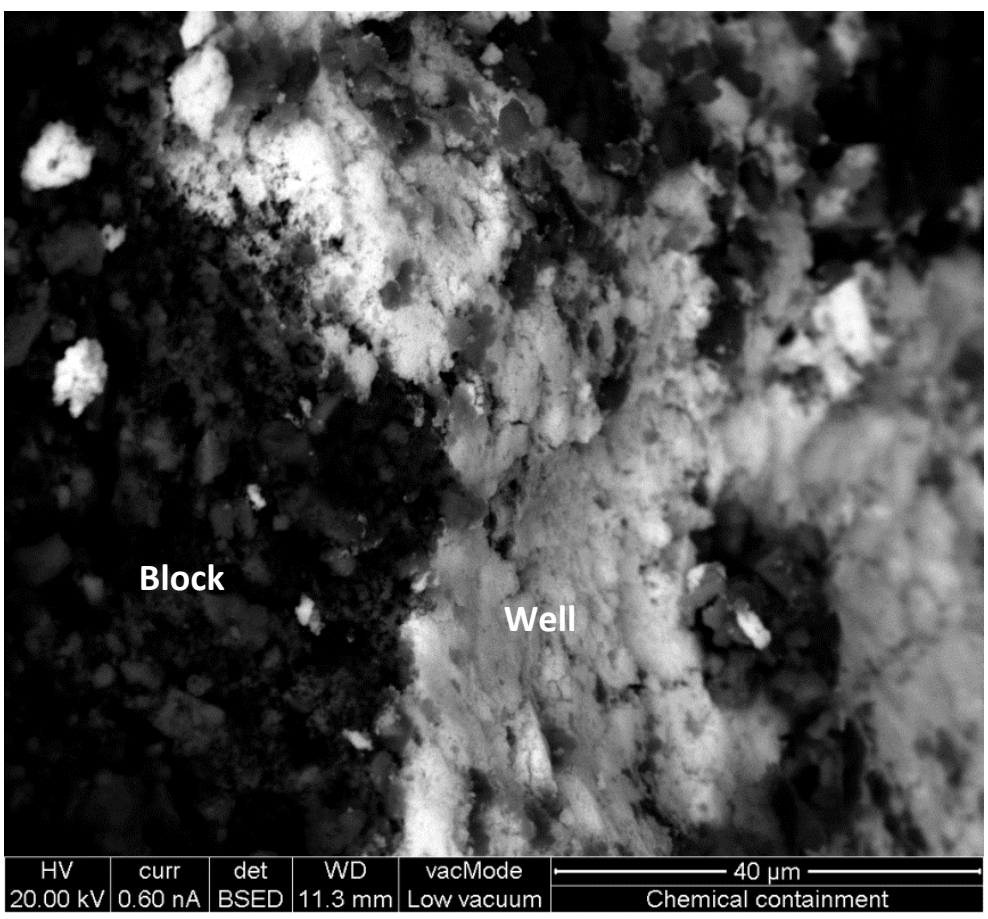

99

100

101

102

103

104

105

106

107

Figure S2

108 
(a)

(b)
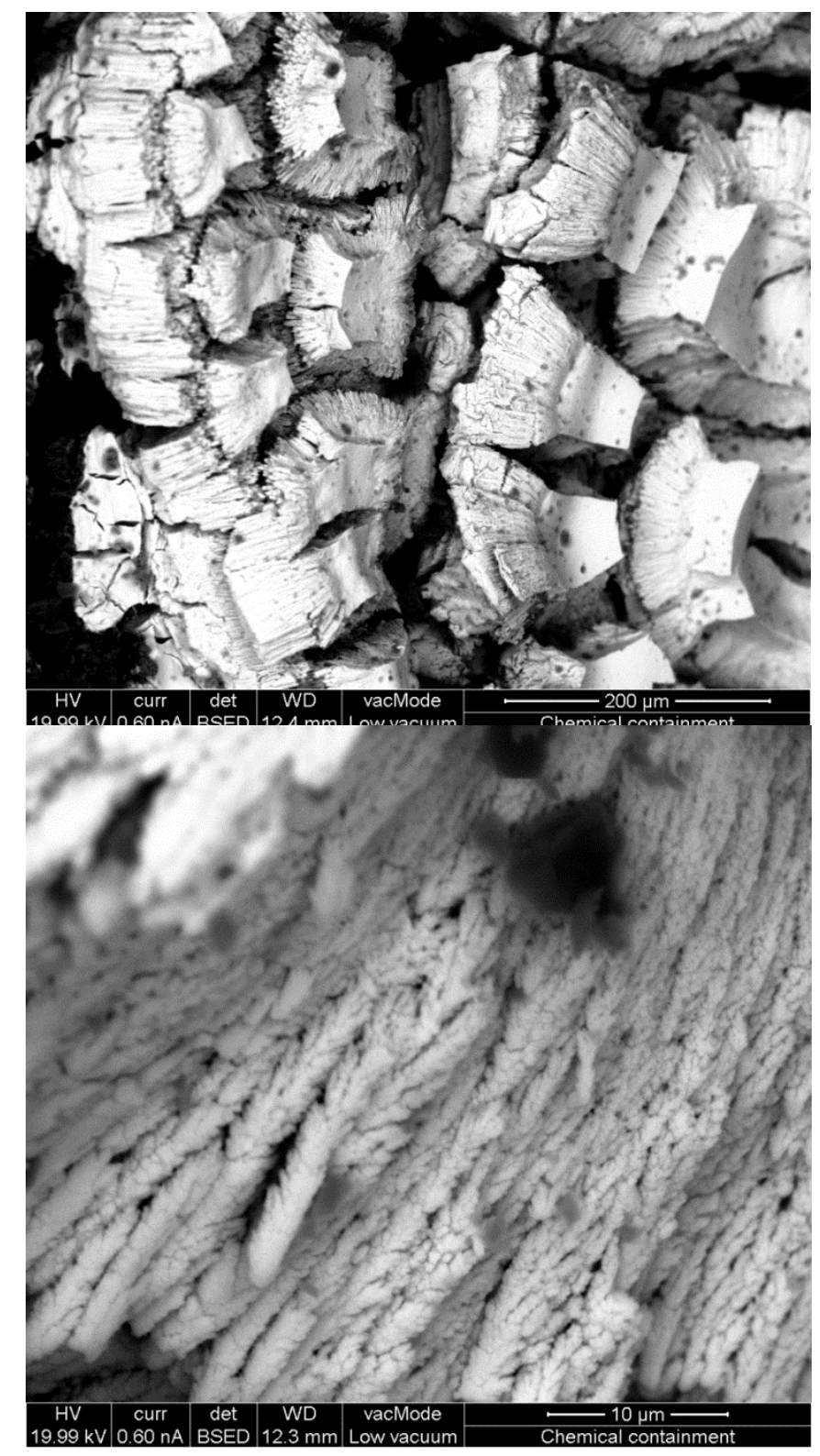
151

152

153

154

155

156

157

158

159

160

161

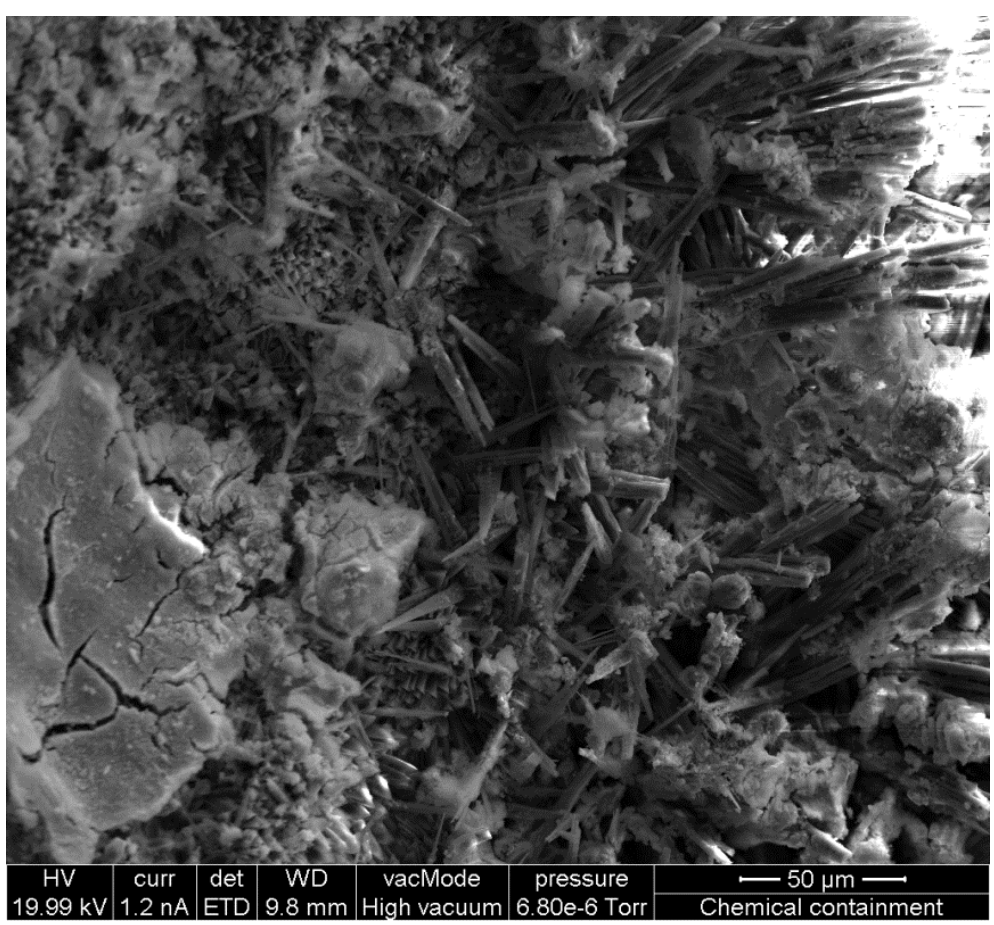

\section{2}

4

\section{5}

56

57

Figure S4 
(a)

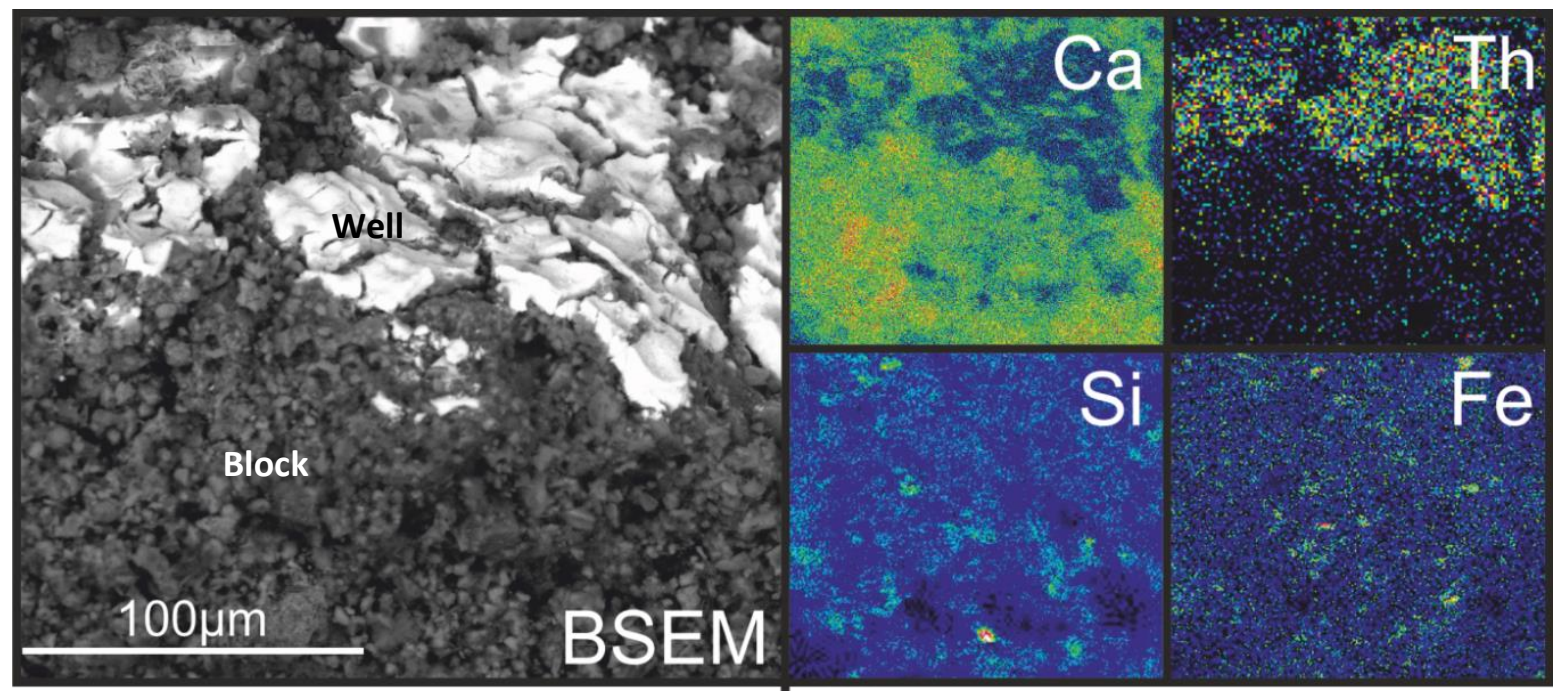

174 $100 \mu \mathrm{m}$

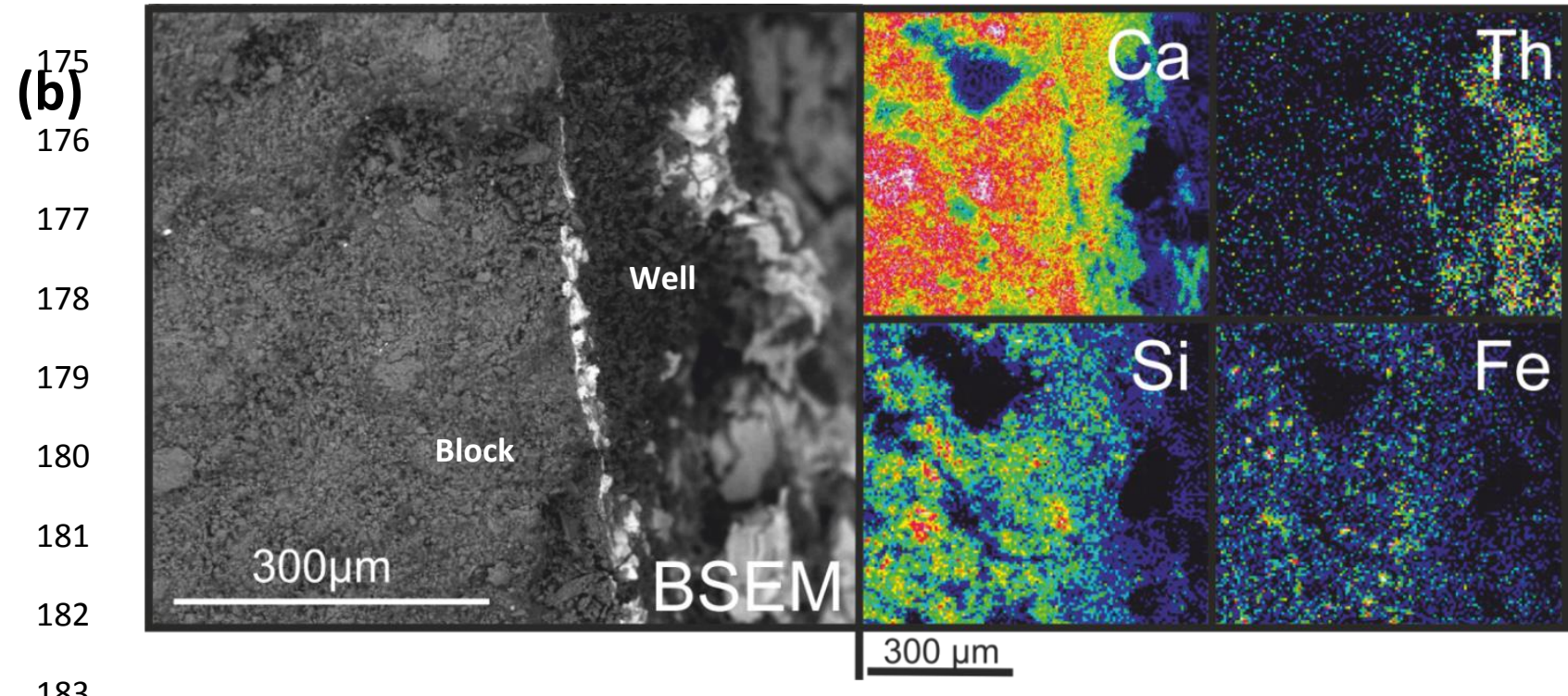


191

192

193

194

195

196

197 